\title{
Meta-type analysis of dopaminergic effects on gene expression in the neuroendocrine brain of female goldfish
}

\author{
Jason T. Popesku ${ }^{1}{ }^{*}$, Christopher J. Martyniuk ${ }^{2}$ and Vance L. Trudeau ${ }^{1}$ * \\ ' Centre for Advanced Research in Environmental Genomics, Department of Biology, University of Ottawa, Ottawa, ON, Canada \\ ${ }^{2}$ Canadian Rivers Institute and Department of Biology, University of New Brunswick, Saint John, NB, Canada
}

\author{
Edited by: \\ Wei Ge, The Chinese University of \\ Hong Kong, China \\ Reviewed by: \\ José A. Muñoz-Cueto, University of \\ Cadiz, Spain \\ Anderson O. Wong, The University of \\ Hong Kong, Hong Kong \\ *Correspondence: \\ Jason T. Popesku, Centre for \\ Advanced Research in Environmental \\ Genomics, Department of Biology, \\ University of Ottawa, Ottawa, ON, \\ Canada K1N 6N5. \\ e-mail: jpopesku@gmail.com \\ Vance L. Trudeau, Department of \\ Biology, University of Ottawa, Room \\ 160, Gendron Hall, 30 Marie Curie, \\ Ottawa, ON, Canada K1N 6N5. \\ e-mail: trudeauv@uottawa.ca

\section{${ }^{\dagger}$ Present address:} \\ Jason T. Popesku, Department of \\ Cellular and Physiological Sciences, \\ Life Sciences Institute, University of \\ British Columbia, Vancouver, BC, \\ Canada V6T $1 Z 3$.
}

Dopamine (DA) is a major neurotransmitter important for neuroendocrine control and recent studies have described genomic signaling pathways activated and inhibited by DA agonists and antagonists in the goldfish brain. Here we perform a meta-type analysis using microarray datasets from experiments conducted with female goldfish to characterize the gene expression responses that underlie dopaminergic signaling. Sexually mature, pre-spawning [gonadosomatic index $(\mathrm{GSI})=4.5 \pm 1.3 \%$ ] or sexually regressing $(\mathrm{GSI}=3 \pm 0.4 \%$ ) female goldfish (15-40 g) injected intraperitoneally with either SKF 38393, LY 171555, SCH 23390, sulpiride, or a combination of 1-methyl-4-phenyl-1,2,3,6-tetrahydropyridine and $\alpha$-methyl-ptyrosine. Microarray meta-type analysis identified 268 genes in the telencephalon and hypothalamus as having reciprocal (i.e., opposite between agonism and antagonism/depletion) fold change responses, suggesting that these transcripts are likely targets for DA-mediated regulation. Noteworthy genes included ependymin, vimentin, and aromatase, genes that support the significance of DA in neuronal plasticity and tissue remodeling. Sub-network enrichment analysis (SNEA) was used to identify common gene regulators and binding proteins associated with the differentially expressed genes mediated by DA. SNEA analysis identified gene expression targets that were related to three major categories that included cell signaling (STAT3, SP1, SMAD, Jun/Fos), immune response (IL-6, IL-1 $\beta$, TNFs, cytokine, NF-KB), and cell proliferation and growth (IGF1, TGF $\beta 1$ ). These gene networks are also known to be associated with neurodegenerative disorders such as Parkinsons' disease, well-known to be associated with loss of dopaminergic neurons. This study identifies genes and networks that underlie DA signaling in the vertebrate CNS and provides targets that may be key neuroendocrine regulators. The results provide a foundation for future work on dopaminergic regulation of gene expression in fish model systems.

\section{INTRODUCTION}

Dopamine (DA) is a neurotransmitter important in disorders such as schizophrenia (Seeman and Kapur, 2000) and Parkinson's disease (Baik et al., 1995), but is also the major neurotransmitter controlling teleost reproduction (reviewed in Dufour et al., 2005; Dufour et al., 2010). In this regard, DA inhibits the release of luteinizing hormone $(\mathrm{LH})$ in fish through multiple mechanisms: (a) DA inhibits gonadotropin-releasing hormone $(\mathrm{GnRH})$ release from GnRH neurons through the D1 receptor (Yu and Peter, 1992); (b) DA directly inhibits LH release from gonadotrophs in the anterior pituitary through the D2 receptor (Peter et al., 1986; Omeljaniuk et al., 1987); (c) DA decreases the expression of GnRH receptor mRNA in the pituitary (Kumakura et al., 2003; Levavi-Sivan et al., 2004); and (d) DA inhibits the synthesis of GABA (Hibbert et al., 2004, 2005), an important stimulator of LH release (Martyniuk et al., 2007). Furthermore, it is well understood that DA, acting through the D1, stimulates growth hormone in fish (Wong et al., 1992). Our recent studies using goldfish have investigated the effects of DA agonists on the hypothalamic transcriptome and proteome (Popesku et al., 2010) or of DA antagonists on gene expression in the neuroendocrine brain (Popesku et al., 2011a). Additionally, we have previously described the effects of a combination of 1-methyl-4-phenyl-1,2,3,6-tetrahydropyridine (MPTP; a selective DA neurotoxin) and $\alpha$-methyl- $p$-tyrosine ( $\alpha \mathrm{MPT}$; a tyrosine hydroxylase inhibitor) on the goldfish hypothalamic transcriptome (Popesku et al., 2008). Using microarray datasets from two of these experiments, and an additional novel microarray data presented here, we further elucidate the mechanistic effects of DA on gene expression in the neuroendocrine brain by performing a meta-type analysis of these datasets.

In transcriptomics, there are a number of bioinformatics approaches to globally assess gene expression data and to organize expression data into a larger biological context. These methods include Gene Ontology (GO) characterization, functional enrichment, and pathway analysis. Many of these approaches have been successfully performed using genomic data in neuroendocrine regions of teleost fishes to better describe cellular events that are mediated by neurotransmitters, hormones, or exogenous neuroactive agents (Marlatt et al., 2008; Popesku et al., 2008; Zhang et al., 2009a; Martyniuk et al., 2010). New bioinformatics tools are now 
available to construct gene networks using gene expression profiling and have been used successfully in teleost fish (e.g., reverse engineering of adverse pathways for ecotoxicology (Perkins et al., 2011). Sub-network enrichment analysis (SNEA; Ariadne's Pathway Studio v7.0 Sivachenko et al., 2007) offers a unique approach to protein interaction networks that are described in the literature as well as a curated mammalian database. Specifically, SNEA builds sub-networks by mapping experimental data onto known bio-molecular interactions. The interactions include promoterbinding, protein modification, and common targets of expression. This algorithm has been used to identify gene sub-networks in breast cancer cell lines (Chuang et al., 2007) and is a useful tool for identifying interaction or signaling networks that involve differentially expressed genes. As such, this method can provide insight in gene regulatory pathways.

In this study, we identify genes and sub-networks that are likely regulated by DA based on their reciprocal response to DA agonism or antagonism/depletion. These data have implications for our understanding of DA action in fish neuroendocrine systems.

\section{MATERIALS AND METHODS}

This is a meta-type analysis of published experiments involving treatments of goldfish with DA agonists (Popesku et al., 2010), antagonists (Popesku et al., 2011a), and after pharmacological depletion of DA (Popesku et al., 2008). The abbreviated Materials and Methods pertaining to the experiments are included here for completeness. It should be noted that, while published, the previous DA depletion studies offered only a cursory analysis of the microarray data in the context of neurotransmitter effects on gene expression and did not specifically address global dopaminergic control of transcriptional responses. Furthermore, we present novel transcriptomic data for specific DA antagonism for which the physiological response to these antagonists has been published (Popesku et al., 2011a), but for which microarray analysis was not performed at that time. We used this novel dataset to compare these DA antagonism responses to agonist and DA depletion responses to improve identification of DA-regulated transcripts in the hypothalamus.

\section{EXPERIMENTAL ANIMALS AND CONDITIONS}

All procedures used were approved by the University of Ottawa Protocol Review Committee and followed standard Canadian Council on Animal Care guidelines on the use of animals in research.

Common adult female goldfish were purchased from a commercial supplier (Aleong's International Inc., Mississauga, ON, Canada) and maintained at $18^{\circ} \mathrm{C}$ under a natural simulated photoperiod on standard flaked goldfish food. Fish were allowed to acclimate for a minimum of 1 month prior to any experimental manipulations. Goldfish were anesthetized using 3-aminobenzoic acid ethylester (MS222) for all handling, injection, and dissection procedures.

\section{DOPAMINE AGONIST EXPERIMENT}

Sexually mature, pre-spawning [mid-May; gonadosomatic index $(\mathrm{GSI})=4.5 \pm 1.3 \%$ ] female goldfish $(15-40 \mathrm{~g})$ were injected intraperitoneally with either SKF 38393 [D1 agonist; SKF;
1-phenyl-2,3,4,5-tetrahydro-(1H)-3-benzazepine-7,8-diol] or LY 171555 [D2 agonist; LY; (-)-Quinpirole hydrochloride] purchased from Tocris (Ballwin, MO, USA). The experimental design and doses chosen were based on Otto et al. (1999) who showed rapid effects on goldfish brain somatostatin mRNAs. LY was dissolved in physiological saline $(0.6 \% \mathrm{NaCl})$ to yield a dose of $2 \mu \mathrm{g} / \mathrm{g}$ body weight of fish. SKF was first dissolved in a minimal amount of dimethylsulfoxide (DMSO), and subsequently diluted to $40 \mu \mathrm{g} / \mathrm{g}$ body weight of fish with physiological saline $(0.6 \%$ for fish). The final concentration of DMSO was 0.099\%; DMSO up to $0.1 \%$ does not affect basal GH or LH levels (Otto et al., 1999). While 0.1\% DMSO may (Mortensen and Arukwe, 2006) or may not (Nishimura et al., 2008) affect gene expression, all of our gene expression work is relative to control fish which received an equivalent amount of DMSO. The fish received two sequential i.p. injections at $5 \mu \mathrm{L} / \mathrm{g}$ body weight each according to the schedule shown in Table 1. The experiment was conducted this way to ensure that all fish received an equivalent volume of vehicle.

\section{DOPAMINE ANTAGONIST EXPERIMENT}

The DA D1-specific antagonist SCH 23390 and DA D2-specific antagonist sulpiride were purchased from Tocris (Ballwin, MO, USA). The antagonists were first dissolved in a minimal amount of DMSO, and subsequently diluted with $0.6 \%$ saline. The final concentration of DMSO was $0.099 \%$. Sexually regressing (June; GSI $=3 \pm 0.4 \% ; n=18$ each) female goldfish received a single injection at $5 \mu \mathrm{L} / \mathrm{g}$ body weight of either SCH 23390 or sulpiride to give a dose of $40 \mu \mathrm{g} / \mathrm{g}$ or $2 \mu \mathrm{g} / \mathrm{g}$ body weight of fish, respectively, or saline containing an equivalent amount of DMSO.

\section{DOPAMINE DEPLETION EXPERIMENT}

1-Methyl-4-phenyl-1,2,3,6-tetrahydropyridine and $\alpha$-methyl- $p$ tyrosine $(\alpha \mathrm{MPT})$ were purchased from Sigma-Aldrich (St. Louis, MO, USA). Sexually mature (May; GSI $=4.7 \pm 0.6 \%$ ) female goldfish $(n=5$ each) were injected with MPTP ( $50 \mu \mathrm{g} / \mathrm{g}$; day 0$)$ and $\alpha \mathrm{MPT}(240 \mu \mathrm{g} / \mathrm{g}$; day 5) or saline (control) in order to severely deplete catecholamines. Our previous work had established effective doses of MPTP and $\alpha$ MPT in goldfish (Trudeau et al., 1993; Hibbert et al., 2004).

\section{TISSUE DISSECTIONS}

Fish were sacrificed by spinal transection and hypothalami and telencephali tissues were rapidly dissected and immediately frozen on dry ice. Brain tissues were pooled (2-3 hypothalami or telencephali/tube) to increase RNA yield prior to RNA isolation. For the agonists and antagonists, tissues were harvested $5 \mathrm{~h}$ post-injection, and for the DA depletion experiment, tissues were harvested $20 \mathrm{~h}$ after the $\alpha$ MPT injection. The cerebellae of the fish from the DA

Table 1 | Injection schedule for the administration of dopamine agonists used in this study.

\begin{tabular}{llll}
\hline Treatment & i.p. Injection 1 & i.p. Injection 2 & \# Fish injected \\
\hline Control & $0.1 \%$ DMSO/saline & $0.6 \%$ Saline & 13 \\
SKF & SKF $3839340 \mu \mathrm{g} / \mathrm{g}$ & $0.6 \%$ Saline & 14 \\
LY & $0.1 \%$ DMSO/saline & LY $1715552 \mu \mathrm{g} / \mathrm{g}$ & 11
\end{tabular}


depletion experiment were also harvested for brain catecholamine levels, but were not used in further analyses.

\section{RNA ISOLATION, QUANTIFICATION, AND QUALITY ASSESSMENT}

RNA was isolated with the TRIzol method (Invitrogen, Burlington, ON, Canada) per the manufacturer's protocol. Samples were treated with DNase on-column in an RNeasy Mini Plus kit (Qiagen, Mississauga, ON, Canada). RNA quantity was evaluated using the NanoDrop ND-1000 spectrophotometer (Thermo Fisher Scientific). RNA integrity was evaluated using the BioAnalyzer (Agilent); RIN for each sample was $>8.4$.

\section{HPLC ANALYSIS OF BRAIN CATECHOLAMINE LEVELS IN THE DOPAMINE DEPLETION EXPERIMENT}

Catecholamine levels in brain tissues were determined on aluminaextracted samples $(100 \mu \mathrm{L})$ using HPLC with electrochemical detection (Woodward, 1982). The HPLC incorporated a Varian ProStar 410 solvent delivery system (Varian Chromatography Systems, Walnut Creek, CA, USA) coupled to a Princeton Applied Research 400 electrochemical detector (EG \& G Instruments, Princeton, NJ, USA). Concentrations were calculated relative to appropriate standards, using 3,4-dihydroxybenzalamine hydrobromide (DHBA) as an internal standard.

\section{MICROARRAY HYBRIDIZATIONS}

For all microarray analyses, cDNA was synthesized from $2 \mu \mathrm{g}$ total RNA according to the Genisphere 3DNA Array 900MPX kit according to the manufacturer's protocol (Genisphere, Hatfield, PA, USA). We previously described and validated the production and use of our goldfish-carp cDNA microarray (Martyniuk et al., 2006; Marlatt et al., 2008; Mennigen et al., 2008), and a detailed description of the microarray is available (Williams et al., 2008). Four microarray hybridizations were performed for each hypothalamic and telencephalic tissue pool for both D1 and D2 agonists (total of 16 arrays), antagonists (16 arrays), or DA depletion $(\mathrm{MPTP}+\alpha \mathrm{MPT}$; eight arrays) to screen for the effects of the DA in the neuroendocrine brain. For each experiment, three separate pools of RNA from treated fish were hybridized to the microarrays, and a fourth hybridization was a replicate dye-reversal of one of the three RNA pooled samples. Hybridizations were carried out relative to a common pool of control samples ( $\sim 30$ control fish) for each tissue, which decreases technical variation as only one reference is utilized while maintaining biological variation of the treatment samples (Churchill, 2002). All cDNA synthesis, labeling, and hybridizations were performed using the Genisphere 3DNA Array 900MPX kit according to the manufacturer's protocol (Genisphere, Hatfield, PA, USA). Hybridizations and scanning protocols were described previously (Martyniuk et al., 2006; Marlatt et al., 2008; Mennigen et al., 2008). Briefly, microarrays were scanned at full-speed $10-\mu \mathrm{m}$ resolution with the ScanArray 5000 XL system (Packard Biosciences/PerkinElmer, Woodbridge, ON, Canada) using both red and blue lasers. Images were obtained with ScanArray Express software using automatic calibration sensitivity varying photomultiplier (PMT) gain (PMT starting at 65\% for $\mathrm{Cy} 5$ and $70 \%$ for $\mathrm{Cy} 3$ ) with fixed laser power at $80 \%$ and the target intensity set for $90 \%$. Microarray images were analyzed with QuantArray (Packard Biosciences/Perkin Elmer), and raw signal intensity values were obtained for duplicate spots of genes. Raw intensity values for all microarray data and microarray platform information have been deposited in the NCBI Gene Expression Omnibus database and assigned the following SuperSeries accession numbers: GSE15855 (agonists), GSE15763 (antagonists), and GSE16044 (MPTP $+\alpha$ MPT). Generalized Procrustes Analysis (Xiong et al., 2008) was used for normalization of the array data and the Significance Analysis of Microarrays (SAM) method (Woodward, 1982; Tusher et al., 2001) was used to identify differentially expressed genes. Genes/ESTs were selected based on identical AURATUS GeneIDs and on the basis of differential regulation in opposite directions for MPTP or the antagonists vs. agonists, or in the same direction for MPTP vs. antagonists; genes that did not fall into one of these categories were not included in the analysis. All genes/ESTs identified and presented were statistically significant $(q<5 \%)$ in all treatments.

\section{REAL-TIME PCR}

Primers used in this study for aromatase B, 18S, and $\beta$-actin have been validated and published (Martyniuk et al., 2006). The Mx3005 Multiplex Quantitative PCR System (Stratagene, La Jolla, CA, USA) was used to amplify and detect the transcripts of interest. Each PCR reaction contained the following final concentrations: $25 \mathrm{ng}$ first strand cDNA template, $1 \times$ QPCR buffer, $3 \mathrm{mM} \mathrm{MgCl} 2$, $300 \mathrm{nM}$ each $\mathrm{F} \& \mathrm{R}$ primers, $0.25 \times$ SYBRGreen (Invitrogen), $200 \mu \mathrm{M}$ dNTPs, 1.25 U HotStarTaq (Invitrogen), and $100 \mathrm{nM} \mathrm{ROX}$ reference dye, in a $25 \mu \mathrm{L}$ reaction volume. The thermal cycling parameters were an initial one cycle Taq activation at $95^{\circ} \mathrm{C}$ for $10 \mathrm{~min}$, followed by 40 cycles of $95^{\circ} \mathrm{C}$ for $30 \mathrm{~s}, 59^{\circ} \mathrm{C}$ for $45 \mathrm{~s}$, and $72^{\circ} \mathrm{C}$ for $30 \mathrm{~s}$. After the reaction was complete, a dissociation curve was produced starting from $55^{\circ} \mathrm{C}\left(+1^{\circ} \mathrm{C} / 30 \mathrm{~s}\right)$ to $95^{\circ} \mathrm{C}$. Dilutions of cDNA (1:10-1:31,250) from all samples were used to construct a relative standard curve for each primer set, relating initial template copy number to fluorescence and amplification cycle. For each PCR reaction, negative controls were also introduced including a no-template control (NTC) where RNase-free water was added to the reaction instead of the template (cDNA) and NoRT control, where water was added instead of reverse transcriptase during cDNA synthesis. The SYBR green assay for each target gene was optimized for primer concentration and annealing temperature to obtain, for the standard curve, an $R^{2}>0.99$, amplification efficiency between 90 and $110 \%$ and a single sequence-specific peak in the dissociation curve. No amplification was observed in the NoRT or NTC controls indicating no genomic or reagent contamination. Data were analyzed with the MxPro v4.01 software package.

\section{SUB-NETWORK ENRICHMENT ANALYSIS OF RECIPROCALLY DA-REGULATED TRANSCRIPTS}

Pathway Studio 7.1 (Ariadne, Rockville, MD, USA) and ResNet 7.0 were used for SNEA for genes that showed reciprocal expression with MPTP-mediated DA depletion and with the DA agonist SKF 38393. We selected the agonist and DA depletion datasets from the hypothalamus for this analysis because (1) the experiments were conducted at the same time of year (May) and (2) these experiments resulted in the greatest number of reciprocal gene expression changes. A total of 114 genes were successfully mapped to human homologs using the GenBank protein ID while 14 genes 
could not be confidently mapped to human homologs; hence the unmapped proteins were not included in the analysis. SNEA for expression targets, binding partners, and post-translation modification targets was performed to determine if there were common gene targets for MPTP and SKF treatments. SNEA creates a central "seed" from all relevant entities in the database, to find common effectors (expression targets, binding partners, and posttranslational targets). The enrichment $p$-value for gene seeds was set at $p<0.05$ and, for the current study, the criteria of greater than five members per group were required for inclusion as a significantly regulated gene network. This was chosen to focus the analysis and discussion on the most likely gene networks regulated through DA signaling.

\section{RESULTS}

\section{CATECHOLAMINE DEPLETION}

To ensure that the MPTP $+\alpha \mathrm{MPT}$ treatment effectively decreased DA levels in the brain, Hyp, Tel, and cerebellum (Cer) tissues were analyzed for catecholamine content using HPLC. Following injections of MPTP ( -6 days) and $\alpha \mathrm{MPT}(-1$ day), DA levels were decreased by 69.6 and $70.9 \%$ in the Hyp and Tel, respectively, and by $88.2 \%$ in the Cer relative to saline-injected controls (Figure 1). Norepinephrine (NE) levels were also reduced in the Hyp (79.4\%), Tel (87.5\%), and Cer (90.4\%).

\section{MICROARRAY ANALYSIS}

Using the microarray datasets from our previous experiments (Popesku et al., 2008, 2010), and the novel microarray data from the antagonist experiment, a meta-type analysis of genes likely regulated by DA was performed. A total of 268 genes/ESTs were identified in the hypothalamus as being regulated by DA, while only four were identified in the telencephalon. Of the 268 genes/ESTs identified in the hypothalamus, only $41 \%$ are annotated (Figure A1 in Appendix). The others currently have no known biological function (6\%), are not similar to any sequences in GenBank (34\%), or are lacking sequence information (19\%). The relatively high number of sequences affected by DA in the hypothalamus, the majority of which are acting through the D1 receptor (Table 2), highlights

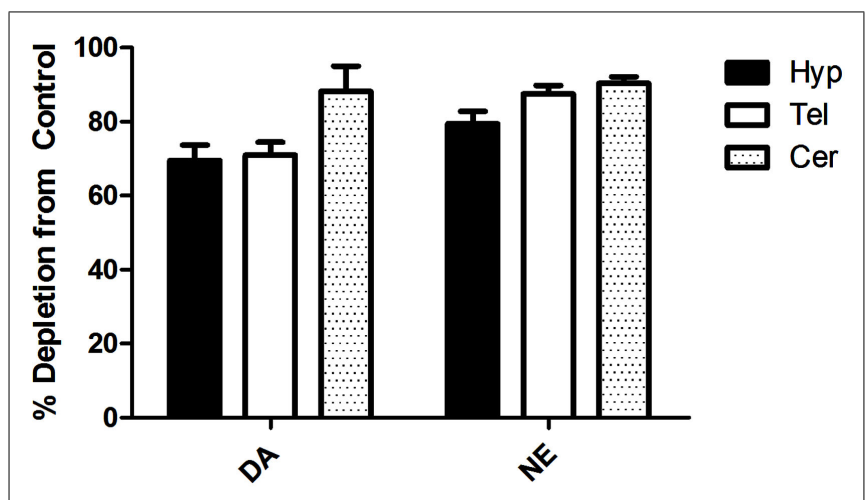

FIGURE 1 | Percent depletion of dopamine (DA) and norepinephrine (NE) in different brain tissues relative to saline-injected control 6d post-injection with MPTP and 1d post-injection with $\alpha$ MPT $(p<0.01$ in all cases, relative to control). Tel, Telencephalon; Hyp, Hypothalamus; Cer, Cerebellum. the importance of this receptor in this tissue. The annotated sequences were binned into their corresponding GO Slim terms, using Blast2GO as described in Popesku et al., 2010; Figure 2).

\section{REAL-TIME RT-PCR VALIDATION OF AromB}

Changes in the hypothalamic mRNA levels of Aromatase B identified by microarray analysis were validated using real-time RT-PCR. Figure 3 shows a 4.7 -fold decrease $(p=0.027)$ in AromB mRNA levels $5 \mathrm{~h}$ post-injection with SKF 38393. AromB mRNA levels were increased 1.6-fold following DA depletion, but did not reach statistical significance $(p>0.05)$.

\section{SNEA}

Sub-network enrichment analysis identified a number gene set targets for MPTP-mediated DA depletion and SKF 38393 (Table 3). Expression targets of insulin (INS) were highly affected by DA deletion and receptor stimulation (Figure 4A). This expression group included genes such as apoe and apoa4, vim, gapdh, and myc. Expression targets also affected by DA depletion and SKF 38393 were those related to cell signaling, for example expression targets of STAT3, SMAD, JUN, and SP1 signaling. A second major group of expression targets included those related to inflammation such as cytokines, NF- $\kappa \mathrm{B}$, IL-6, IL- $1 \beta$, and TNF. Genes involved in cytokine signaling that are reciprocally affected by dopaminergic stimulation/inhibition included fn1, cyp19a1, psmd4, vim, and glul (Figure 4B). The third group involved expression targets related to cell growth and differentiation such as insulin-like growth factor I (IGF1) and transforming growth factor-beta (TGF $\beta 1$; Figure 4C). Also noteworthy was that expression targets of HIF1A were also identified in the SNEA analysis (Table 3). SNEA is also able to identify binding partner networks and post-translational targets using differentially expressed genes. Binding partners of vitamin D, GAPDH, myosin, and tubulin were affected by treatments while protein modification targets of trypsin and glutathione transferase were significantly impacted through DA signaling (Table 3).

\section{DISCUSSION}

Our approach is an effort to identify a group of genes that are likely regulated by DA. The principle behind the analysis is that genes commonly affected in one direction by severe catecholamine depletion $(\mathrm{MPTP}+\alpha \mathrm{MPT})$ and/or DA antagonists will also be affected by DA agonists but expression changes will be in the opposite direction. The power and novelty of this analysis lies in the physiological manipulation and biological validation of reciprocal fold-changes between DA agonists and antagonists/depletion in vivo, rather than the technical validation resulting from different techniques performed on the same samples. Additionally, we validated the expression of brain aromatase in the hypothalamus (discussed below) using real-time RT-PCR.

Here we present transcripts that are affected by wellcharacterized dopaminergic manipulations and allow for speculation on DAergic mechanisms of action in the goldfish neuroendocrine brain. Furthermore, our analysis identified gene networks and provides the foundation for future work on DAergic regulation of neuroendocrine gene expression. Some of the genes/ESTs identified in this analysis (e.g., calmodulin, apolipoprotein) were previously discussed (Popesku et al., 2010) and will not be 
Table 2 | Genes/ESTs identified as regulated by dopamine, presented as fold-changes.

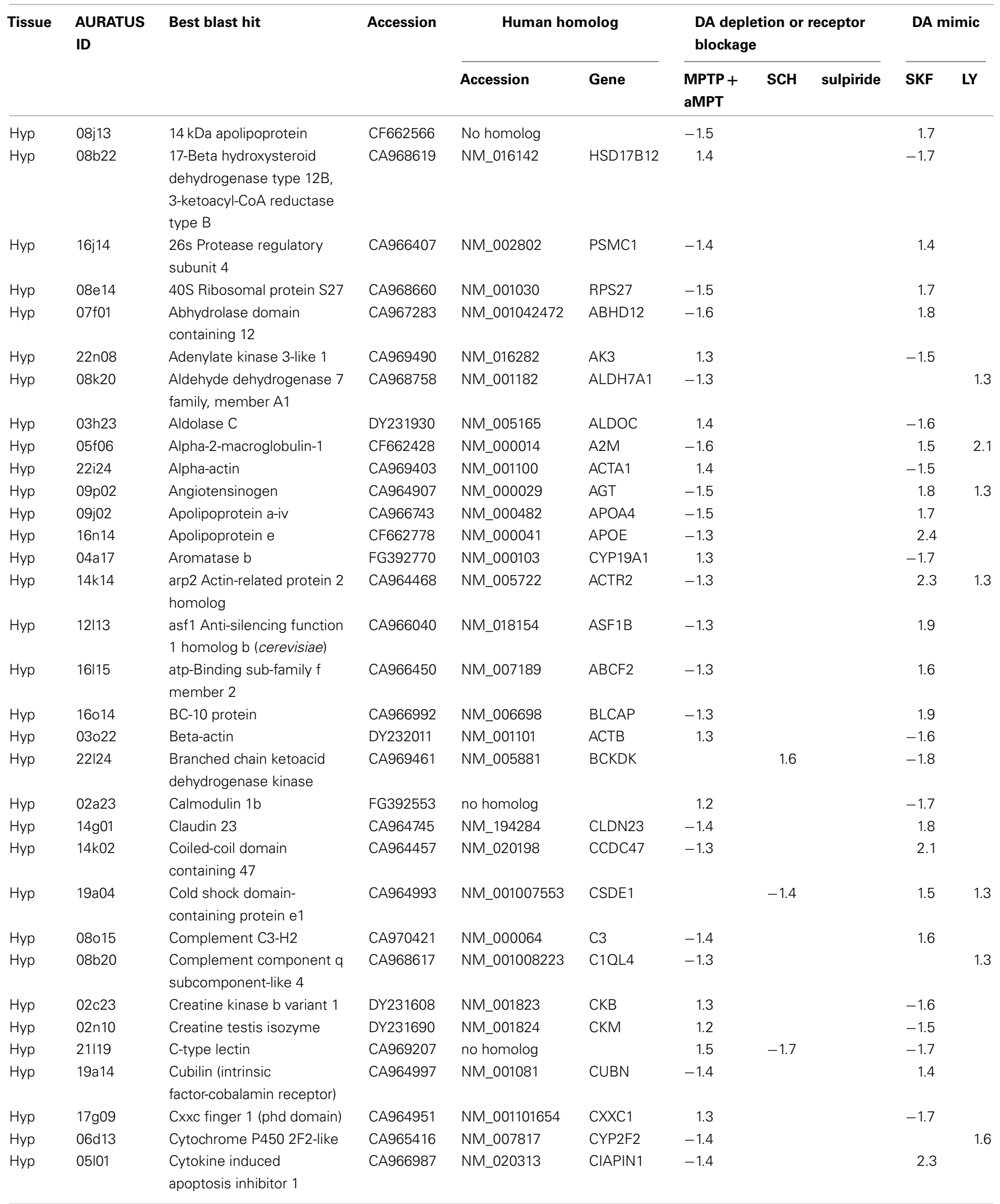


Table 2 | Continued

\begin{tabular}{|c|c|c|c|c|c|c|c|c|c|c|}
\hline \multirow[t]{2}{*}{ Tissue } & \multirow[t]{2}{*}{$\begin{array}{l}\text { AURATUS } \\
\text { ID }\end{array}$} & \multirow[t]{2}{*}{ Best blast hit } & \multirow[t]{2}{*}{ Accession } & \multicolumn{2}{|c|}{ Human homolog } & \multicolumn{3}{|c|}{$\begin{array}{l}\text { DA depletion or receptor } \\
\text { blockage }\end{array}$} & \multicolumn{2}{|c|}{ DA mimic } \\
\hline & & & & Accession & Gene & $\begin{array}{l}\text { MPTP + } \\
\text { aMPT }\end{array}$ & $\mathrm{SCH}$ & sulpiride & SKF & LY \\
\hline Hyp & $03 f 23$ & Deoxyribonuclease I-like 3 & DY231911 & NM_004944 & DNASE1L3 & 1.5 & & & -1.5 & \\
\hline Hyp & $23 k 24$ & e3 Ubiquitin protein ligase & CA968074 & NM_007013 & WWP1 & 1.6 & & & -1.6 & \\
\hline Hyp & 24a12 & eph Receptor a7 & CA969719 & NM_004440 & EPHA7 & 1.6 & & & -2.1 & \\
\hline Hyp & $15 a 10$ & $\begin{array}{l}\text { Equilibrative nucleoside } \\
\text { transporter } 1\end{array}$ & CA965545 & NM_001078174 & SLC29A1 & 1.3 & & & -1.6 & \\
\hline Hyp & 07b01 & $\begin{array}{l}\text { Eukaryotic translation } \\
\text { elongation factor-1 gamma }\end{array}$ & CA966738 & NM_001404 & EEF1G & -1.5 & & & 1.7 & \\
\hline Hyp & $24 \mathrm{j} 21$ & fk506-Binding protein 1a & CA966789 & NM_054014 & FKBP1A & 1.3 & & & -1.5 & \\
\hline Hyp & 03009 & $\begin{array}{l}\text { Fructose-bisphosphate } \\
\text { aldolase c }\end{array}$ & FG392624 & NM_005165 & ALDOC & 1.4 & & & -1.6 & \\
\hline Hyp & $10 \mathrm{~m} 11$ & $\begin{array}{l}\text { g Protein-coupled family } \\
\text { group member c }\end{array}$ & CA967701 & NM_024051 & GGCT & 1.3 & & & -1.6 & \\
\hline Hyp & $17 n 11$ & $\begin{array}{l}\text { Gamma-glutamyl } \\
\text { cyclotransferase }\end{array}$ & CA965786 & NM_024051 & $\mathrm{GGCT}$ & 1.3 & & & -1.7 & \\
\hline Hyp & 03i20 & Glutamine synthetase & DY231974 & NM_001033044 & GLUL & 1.2 & & & -1.5 & \\
\hline Hyp & $10 \mathrm{~d} 04$ & Glutathione peroxidase 3 & CA964192 & NM_002084 & GPX3 & 1.4 & & & -1.5 & \\
\hline Hyp & 23012 & $\begin{array}{l}\text { Glyceraldehyde } \\
\text { 3-phosphate } \\
\text { dehydrogenase }\end{array}$ & CA968103 & NM_002046 & GAPDH & 2.0 & & & -2.1 & \\
\hline Hyp & $14 \mathrm{i} 04$ & HECT domain containing 1 & CA964417 & NM_015382 & HECTD1 & & -1.4 & & 1.5 & \\
\hline Hyp & 24012 & Hexokinase I & CA969997 & NM_000188 & HK1 & 1.6 & & & -1.9 & \\
\hline Hyp & $08 g 14$ & $\begin{array}{l}\text { High-density lipoprotein } \\
\text { binding protein }\end{array}$ & CA968690 & NM_005336 & HDLBP & -1.4 & & & 1.6 & \\
\hline Hyp & 19d02 & $\begin{array}{l}\text { Hydroxysteroid (17-beta) } \\
\text { dehydrogenase } 10\end{array}$ & CA965806 & NM_001037811 & HSD17B10 & -1.3 & & & 2.2 & 1.3 \\
\hline Hyp & $03 i 10$ & $\begin{array}{l}\text { Immunoglobulin mu heavy } \\
\text { chain }\end{array}$ & FG392590 & XM_003120441 & LOC100510678 & 1.5 & & & -1.5 & \\
\hline Hyp & $04 \mathrm{j} 23$ & $\begin{array}{l}\text { Jumonji domain } \\
\text { containing } 3\end{array}$ & FG392963 & NM_001080424 & KDM6B & 1.3 & & & -1.5 & \\
\hline Hyp & 13014 & Latexin & CF662717 & NM_020169 & LXN & & -1.7 & & 1.6 & \\
\hline Hyp & $22 \mathrm{~g} 07$ & $\begin{array}{l}\text { Leucine-rich repeat (in flii) } \\
\text { interacting protein } 1\end{array}$ & CA969350 & NM_001137550 & LRRFIP1 & 1.2 & & & -1.7 & \\
\hline Hyp & $11 \mathrm{p} 01$ & $\begin{array}{l}\text { Leucine-rich repeat } \\
\text { containing } 58\end{array}$ & CF662658 & NM_001099678 & LRRC58 & -1.3 & & & 2.2 & \\
\hline Hyp & $19 f 13$ & Loc548392 protein & CA969104 & unknown & & -1.4 & & & 2.0 & \\
\hline Hyp & $14 \mathrm{~m} 01$ & $\begin{array}{l}\text { Malate dehydrogenase } 1, \\
\text { NAD (soluble) }\end{array}$ & CA964750 & NM_005917 & $\mathrm{MDH} 1$ & -1.3 & & & 1.8 & 1.3 \\
\hline
\end{tabular}


Table 2 | Continued

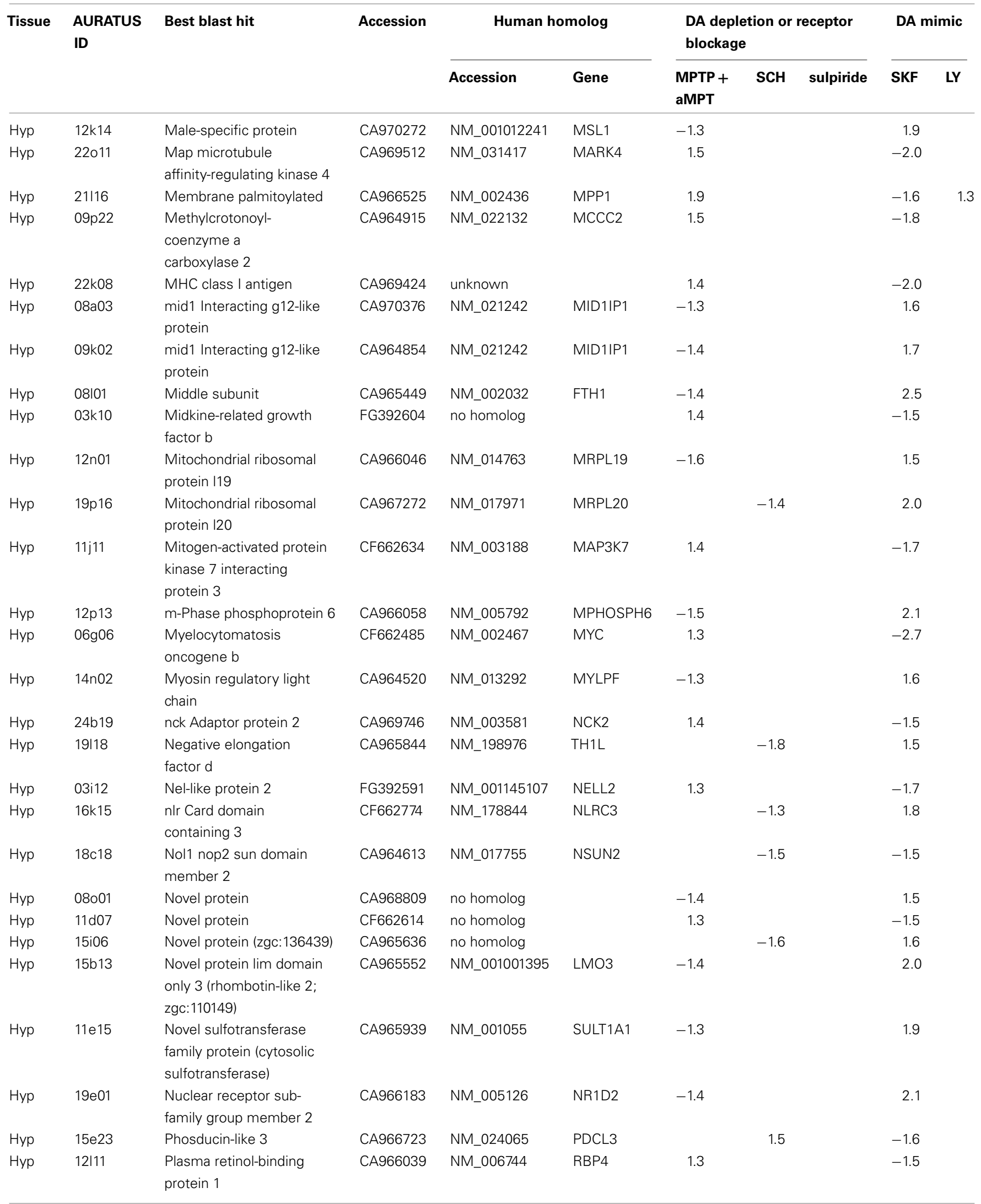


Table 2 | Continued

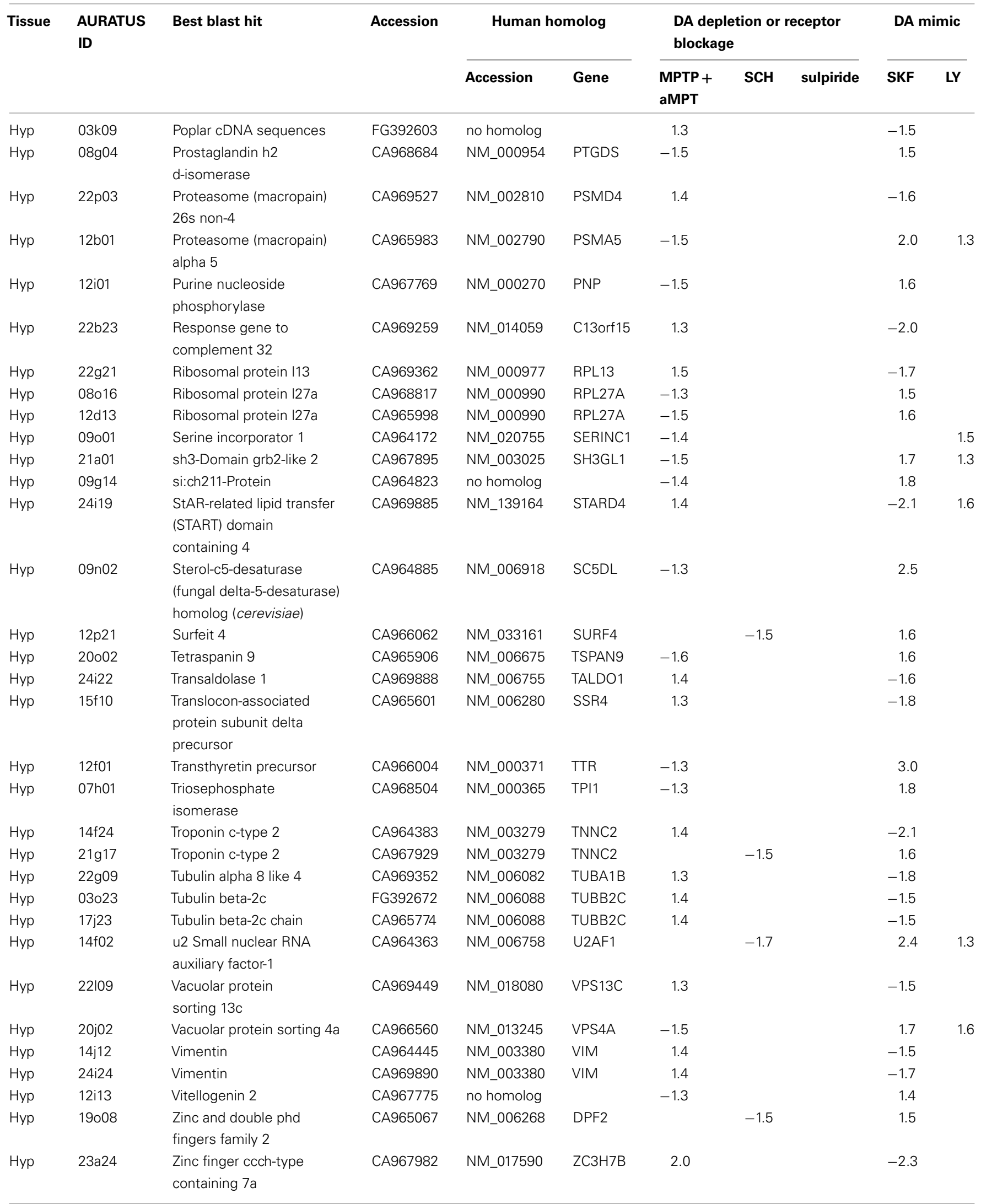


Table 2 | Continued

\begin{tabular}{|c|c|c|c|c|c|c|c|c|c|c|}
\hline \multirow[t]{2}{*}{ Tissue } & \multirow[t]{2}{*}{$\begin{array}{l}\text { AURATUS } \\
\text { ID }\end{array}$} & \multirow[t]{2}{*}{ Best blast hit } & \multirow[t]{2}{*}{ Accession } & \multicolumn{2}{|c|}{ Human homolog } & \multicolumn{3}{|c|}{$\begin{array}{l}\text { DA depletion or receptor } \\
\text { blockage }\end{array}$} & \multicolumn{2}{|c|}{ DA mimic } \\
\hline & & & & Accession & Gene & $\begin{array}{l}\text { MPTP + } \\
\text { aMPT }\end{array}$ & $\mathrm{SCH}$ & sulpiride & SKF & LY \\
\hline Нyp & $15 i 14$ & Zinc finger protein 782 & CA965639 & NM_001001662 & ZNF782 & -1.3 & & & 2.0 & \\
\hline Hyp & $20 c 13$ & Zona pellucida glycoprotein & CA966260 & no homolog & & & -1.6 & & 1.7 & \\
\hline Tel & $12 \mathrm{e} 10$ & $\begin{array}{l}\text { Leucine-rich ppr-motif } \\
\text { containing }\end{array}$ & CA970240 & NM_133259 & LRPPRC & -1.8 & & & & 1.6 \\
\hline Tel & $14 f 04$ & $\begin{array}{l}\text { Solute carrier family } 2 \\
\text { (facilitated glucose } \\
\text { fructose transporter) } \\
\text { member } 5\end{array}$ & CA964365 & NM_207420 & SLC2A7 & & & -1.3 & & 1.9 \\
\hline
\end{tabular}

ESTS were manually selected based on identical AURATUS GenelDs and on the basis of differential regulation in opposite directions for MPTP or the antagonists vs.

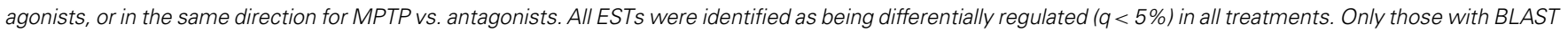

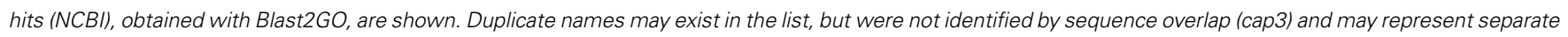

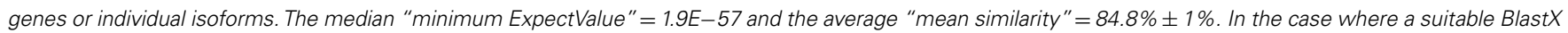

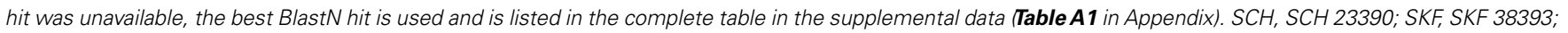
LY, LY 171555.

discussed here. It is not our intention to examine all of the genes/ESTs listed in Table 2, but we have selected some to discuss in terms of current and emerging ideas in dopaminergic neuron (dys)function. The genes/ESTs below are discussed relative to DA receptor stimulation.

The DA agonists and the DA depletion experiments provided the greatest number of reciprocal changes in gene expression compared to the DA antagonist experiment, which is likely due to the fact that both the agonist and depletion experiments were conducted at the same time of year (May) when the fish were of similar sexual maturity (GSI $\sim 4.6 \%$ ) compared to the antagonist experiment (June) when fish were sexually regressing (GSI 3\%). The difference in the number of gene changes between these time points highlights the importance of seasonality of dopaminergic action in the neuroendocrine brain of fish (Zhang et al., 2009b). Indeed, the inhibitory tone of DA on gonadotropin release at these times of year indicate that the fish are in different physiological states (Trudeau et al., 1993; Vacher et al., 2002) and thus may respond to DAergic manipulation differently. This is apparent in some of the genes listed in Table 2 (full list in Table A1 in Appendix), and is a limitation of our approach. We are, however, comparing the effects of DAergic manipulation against paired control fish and are looking for genes that are consistently differentially expressed as a result of that manipulation. While few genes were differentially expressed in the DA antagonist experiment when compared to the other two datasets, the new microarray data presented here provides some further insight into teleost brain function.

Norepinephrine levels were severely reduced in addition to DA levels in MPTP $+\alpha$ MPT-treated fish; however, the genes discussed below are limited to those showing opposite changes to specific DA agonists supporting the hypothesis that genes are therefore likely regulated by DA itself.
The identification of ependymin and vimentin in the hypothalamus highlights the significance of neuronal plasticity and tissue remodeling in response to DAergic manipulations. Ependymin is an extracellular glycoprotein and neurotrophic growth factor involved in optic nerve regeneration, synaptic plasticity, and long-term potentiation in Cypriniformes (Shashoua, 1991; Adams and Shashoua, 1994; Adams et al., 1996). Moreover, ependymin was shown to be overexpressed in regenerating echinoderms (Suarez-Castillo et al., 2004). Ependymin-related proteins were identified in amphibians and mammals (Suarez-Castillo and Garcia-Arraras, 2007) and Shashoua et al. (2001) showed that a short fragment of goldfish ependymin was able to activate the AP-1 transcription factor in neuroblastoma and primary rat brain cortical cultures. Similarly, vimentin is an intermediate filament and is known to increase during cerebellar regeneration in the brown ghost knifefish, Apteronotus leptorynchus (Clint and Zupanc, 2002). At least 2 forms of vimentin exist in goldfish (Glasgow et al., 1994), and while the current analysis is unable to resolve the form(s) of vimentin regulated by DA, it is likely that both of the sequences listed in Table 2 correspond to the same form, as they share nearly identical expression patterns in response to DA. Both vimentin and ependymin, along with $\alpha$ - and $\beta$-actin and tubulins (Table 2) were decreased in response to DA, supporting the role of DA in synaptic plasticity and tissue remodeling (Kauer and Malenka, 2007). Cytoskeletal remodeling is hypothesized to be important for hormone secretion from the anterior pituitary in mammals (Ravindra and Grosvenor, 1990). Furthermore, Ravindra and Grosvenor (1988) demonstrated that domperidone, a D2-specific antagonist that does not cross the blood-brain barrier but can act on the pituitary, increased prolactin (PRL) levels as well as pituitary polymerized tubulin levels, similar to levels seen in suckling rats. This response, the authors observed, was blocked by bromocriptine, a D2-specific agonist supporting a role 


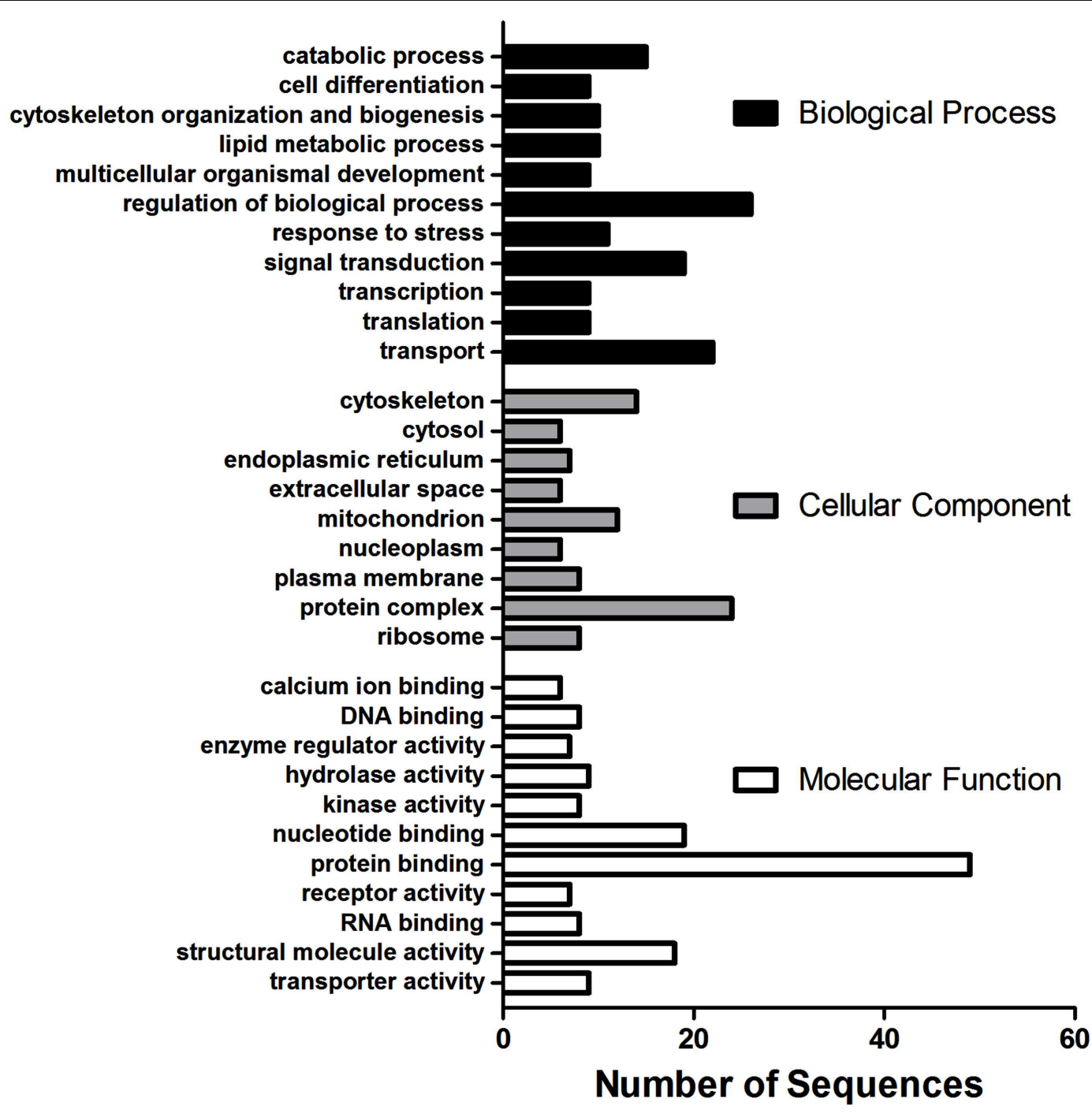

FIGURE 2 | Multilevel Gene Ontology categorization of 110 annotated ESTs regulated by dopamine in the hypothalamus into their corresponding Biological Process, Cellular Component, and Molecular Function terms. GO Annotations were first converted to GO-Slim annotations (goslim_generic.obo) and the multilevel chart was constructed using a sequence convergence cutoff of five (seven for Biological Process) to reduce the complexity of the chart. for DA in changes observed in the tubulin system in the anterior pituitary. This is relevant because, in fish, it should be noted that DAergic neurons in the mediobasal hypothalamus (e.g., posterior tuberculum) project directly to the pituitary (i.e., are hypophysiotropic; Hornby and Piekut, 1990; Anglade et al., 1993). This is important as it suggests the need for maintaining DA neuronal populations throughout seasonal reproductive period. The identification of aromatase b (CYP19B, or AroB) in our analysis as being inhibited by DA is of particular interest. Our RT-PCR targeted validation of the decrease in AroB mRNA levels in response to SKF 38393, it also confirmed an opposite change in direction of AroB mRNA levels in response to DA depletion as identified by the microarray. In adult fish, AroB is expressed only in radial glial cells (Diotel et al., 2010; Le Page et al., 2010), which persist throughout life and serve as neuronal progenitors in the brain.
At least some AroB-immunoreactive (ir) neurons in the medial preoptic area (POA) of the Japanese quail brain respond to DA (Cornil et al., 2004) and a few AroB-ir neurons in the POA of the bluehead wrasse are in close proximity with, while a subset appear to co-express, tyrosine hydrolase (TH; Marsh et al., 2006), the ratelimiting step in DA synthesis and a marker for cathecholaminergic neurons. Moreover, some TH-ir neurons in the POA of rainbow trout express estrogen receptors (Linard et al., 1996) and testosterone and estradiol increase goldfish pituitary DA turnover rates as measured following $\alpha \mathrm{MPT}$-induced catecholamine depletion (Trudeau et al., 1993). More importantly, DA was shown to reduce aromatase enzyme activity in quail POA homogenates in vitro (Baillien and Balthazart, 1997). These studies, including the current one, suggest that DA regulates AroB, possibly to modulate the feedback mechanisms of sex steroids on the brain. However, AroB 


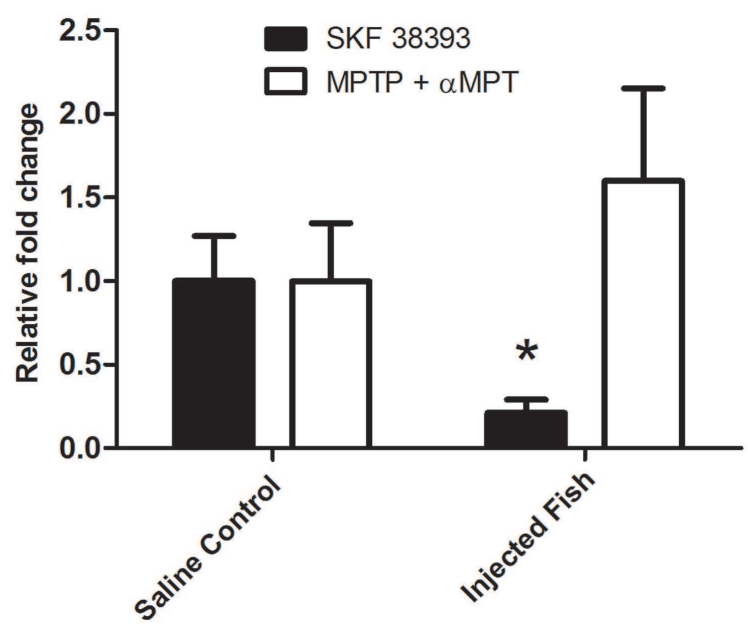

FIGURE 3 | Real-time RT-PCR of aromatase B mRNA levels in the hypothalamus of SKF 38393-injected fish after $5 \mathrm{~h}$ or MPTP $+\alpha$ MPT-injected fish after $24 \mathrm{~h}$. SKF 38393 data were normalized to $\beta$-actin and MPTP $+\alpha$ MPT data were normalized to $18 \mathrm{~S}$ as they were determined to be the most stable for the respective experiments. $A$

Mann-Whitney $U$ Rank Sum test was performed on injected vs. control fish with significance $\left(^{*}\right)$ considered at $p<0.05$ (two-tailed).

is also important in neurogenesis and brain repair (reviewed in Diotel et al., 2010). Interestingly, Pollard et al. (1992) showed full recovery of DA levels in the brain of goldfish after 8 days using a moderate dose of MPTP (50 $\mu \mathrm{g} / \mathrm{g}$ ), and Poli et al. (1992) demonstrated spontaneous recovery of DA and NE levels in the goldfish telencephalon, diencephalon, and medulla after 6 weeks following injection of MPTP at a lower dose $(10 \mu \mathrm{g} / \mathrm{g})$ for three consecutive days. These two studies suggest that in fish, unlike in mammals, DA neurons regenerate following injection with MPTP, and may be linked to higher aromatase activity in the fish brain. This is an avenue of research we are currently conducting.

Multiple genes/ESTs identified as being regulated by DA are involved in the lipid and fatty acid metabolic process or transport. For example, $17 \beta$-hydroxysteroid dehydrogenase type $12 \mathrm{~B}$ (HSD17B12; down), high-density lipoprotein binding protein (HDLBP; up), vitellogenin 2 (vtg2; up), cubulin (CUBN; up), sh3-domain grb-like 2 (SH3GL1; up), StAR-related lipid transfer domain containing 4 (STARD4; down), and sterol-c5-desaturase homolog (SC5DL; up) were identified as being regulated by DA. SC5D is involved in the biosynthesis of cholesterol (Sugawara et al., 2001). HSD17B12 reduces 3-ketoacyl-CoA to 3-hydroxyacylCoA in the second step of fatty acid elongation (Moon and Horton, 2003). In vivo studies in zebrafish demonstrated that HDLBP is not affected by the insulin family or growth hormone, but it is hypothesized that HDLBP is involved in lipid transfer based on its high expression in the liver and ovary (Chen et al., 2003). CUBN is a high-density lipoprotein receptor (Moestrup and Kozyraki, 2000) and STARD4 is hypothesized to facilitate transport of a cholesterol precursor (Soccio et al., 2002). Vtg is best characterized as a liver phosphoprotein stimulated by estrogen and then deposited in the ovary (Jalabert, 2005; Kang et al., 2007), but is, in general, a lipid transport molecule. The changes in these mRNAs suggest lipid mobilization, possibly to derive energy for neuronal remodeling as discussed above.

The granulins are conserved growth factors and are able to stimulate the proliferation of macrophages in goldfish (Hanington et al., 2006). Granulin also has protease inhibitor activity in invertebrates (Hong and Kang, 1999) and cysteine protease activity in plants (Chen et al., 2006). Granulin was shown to be relatively lowly expressed in the brain of goldfish (Hanington et al., 2006) and tilapia (Chen et al., 2007). It appears as though DA, acting through the D1 receptor, stimulates expression of granulin in the hypothalamus of female goldfish. In the developing rat hypothalamus, it was demonstrated that both estrogen and androgen induced granulin expression (Suzuki et al., 2001) and that estrogen induced granulin expression in the dentate gyrus (hippocampus) of adult rats (Chiba et al., 2007). Furthermore, in hippocampal rat tissue in vitro, estradiol enhanced neural progenitor cell proliferation and this response was blocked by a granulinspecific antibody (Chiba et al., 2007). Although speculative, this is relevant, as hydroxysteroid (17 $\beta$ ) dehydrogenase was identified here as being increased in response to DA, which interconverts $17 \beta$-estradiol and estrone, 16- $\alpha$-hydroxyestrone and estriol, and androstenedione and testosterone Stoffel-Wagner (2003), suggesting that sex steroids influence the DAergic regulation of granulin or, alternatively, the DA modulates estrogen-regulated granulin expression.

Granulin mRNA levels were also identified as being decreased 4.2-fold in the goldfish telencephalon following a 2-days waterborne exposure to $0.1 \mu \mathrm{M}$ thyroid hormone (T3; Wiens, 2009). While unconfirmed, this is intriguing because the current study identified transthyretin (TTR) mRNA levels as being significantly increased in response to DA. TTR is a thyroid hormone-binding and transport protein and is necessary for maintaining normal levels of circulating thyroid hormone in plasma (Episkopou et al., 1993). Furthermore, TTR protein levels are increased in the cerebrospinal fluid (CSF) of rats with degenerating nigrostriatal neurons (Rite et al., 2007). Future studies aimed at examining the potential interaction between T3 and DA are warranted, particularly as microarray analysis identified increases in mRNA levels of iodothyronine deiodinase type I in the hypothalamus of female fish in response to SKF 38393 and 171555 (D1- and D2-specific agonists, respectively; Popesku et al., 2010).

The identification of U2 small nuclear RNA auxiliary factor-1 (U2AF1) mRNA levels as being increased by DA acting through the D1 receptor (Table 2) is interesting. There are currently five known small nuclear ribonucleoproteins (snRNPs) that make up the spliceosome (Query, 2009). LSM7 protein, whose mRNA levels were also increased in both DA agonist treatments (Popesku et al., 2010) also forms part of the spliceosome complex (SalgadoGarrido et al., 1999). The increase in both of these factors in response to either DA agonist suggests that blockage of either of these receptors would inhibit transcription of particular components of the spliceosome, and thus decrease splicing activity, thereby decreasing the amount of a particular splice variant. The observed decrease of the D2 short isoform splice variant in response to both D1 and D2 antagonists (Popesku et al., 2011b) supports this hypothesis. 
Table 3 | Sub-network enrichment analysis groupings of genes identified as being regulated by dopamine.

\begin{tabular}{|c|c|c|c|}
\hline Name & Gene set seed & Overlapping entities & $p$-Value \\
\hline \multirow[t]{17}{*}{ Expression targets } & INS & $\begin{array}{l}\text { AGT, FN1, MYC, GAPDH, GLUL, GPX3, APOE, TTR, VIM, C3, APOA4, A2M, } \\
\text { ACTB, FTH1, CKM, BCKDK }\end{array}$ & 1.37E-06 \\
\hline & PGR & FN1, MYC, GAPDH, CYP19A1, C13orf15 & $1.02 \mathrm{E}-03$ \\
\hline & SP1 & $\begin{array}{l}\text { AGT, FN1, MYC, APOE, VIM, C3, SLC29A1, CYP19A1, SH3GL1, SULT1A1, } \\
\text { ASF1B, CKM, BCKDK, CKB, CYP2F1 }\end{array}$ & $1.21 \mathrm{E}-03$ \\
\hline & JUN & FN1, MYC, GLUL, APOE, VIM, A2M, CYP19A1, TPI1 & $1.48 \mathrm{E}-03$ \\
\hline & AKT1 & FN1, MYC, GAPDH, MAP3K7, VIM, A2M, CYP19A1, CKM & $2.10 \mathrm{E}-03$ \\
\hline & CEBPA & AGT, MYC, GAPDH, GLUL, TTR, C3, APOA4, ACTB & $3.63 \mathrm{E}-03$ \\
\hline & SMAD & FN1, MYC, VIM, C13orf15, CKM & $3.92 \mathrm{E}-03$ \\
\hline & IGF1 & AGT, FN1, MYC, VIM, FKBP1A, CYP19A1, TUBA1B, ACTB & $4.86 \mathrm{E}-03$ \\
\hline & HIF1A & FN1, MYC, GAPDH, VIM, SLC29A1, PSMD4 & $7.38 \mathrm{E}-03$ \\
\hline & $\mathrm{PI3K}$ & FN1, MYC, MAP3K7, FKBP1A, SLC29A1, HSP90AB1, CYP19A1, CKM & 8.94E-03 \\
\hline & $N F-k B$ & FN1, MYC, PTGDS, GAPDH, GLUL, GRN, APOE, VIM, C3, A2M, CYP19A1 & 8.97E-03 \\
\hline & TP53 & AGT, FN1, MYC, PTGDS, GAPDH, SLC29A1, HSP90AB1, CKM, PSMD4 & $9.81 \mathrm{E}-03$ \\
\hline & Jun/Fos & FN1, MYC, PTGDS, APOE, TTR, VIM, A2M, CYP19A1, TPI1 & 1.12E-02 \\
\hline & STAT & AGT, FN1, MYC, C3, A2M & $1.55 \mathrm{E}-02$ \\
\hline & CTNNB1 & FN1, MYC, GLUL, VIM, PSMD4 & 1.67E-02 \\
\hline & PKC & FN1, MYC, PTGDS, GLUL, GRN, APOE, HSP90AB1, CYP19A1 & 1.69E-02 \\
\hline & IL-6 & FN1, MYC, APOE, TTR, A2M, HSP90AB1, CYP19A1, CKM & $1.71 \mathrm{E}-02$ \\
\hline \multirow[t]{7}{*}{ Binding partners } & Vitamin D & C3, APOA4, CUBN, ACTA1 & $2.81 \mathrm{E}-05$ \\
\hline & GAPDH & FN1, GAPDH, FKBP1A, TUBA1B & $7.44 \mathrm{E}-04$ \\
\hline & HDL & FN1, TTR, A2M, HDLBP & $1.36 \mathrm{E}-03$ \\
\hline & APP & FN1, TTR, A2M, HSD17B10 & $1.92 \mathrm{E}-03$ \\
\hline & Myosin & GAPDH, VIM, ACTB, MPP1 & $3.63 \mathrm{E}-03$ \\
\hline & Tubulin & MAP3K7, APOE, TPI1, HK1, LRPPRC, EEF1G & $5.21 \mathrm{E}-03$ \\
\hline & ATP & MAP3K7, APOE, HSP90AB1, MCCC2 & $4.82 \mathrm{E}-02$ \\
\hline \multirow[t]{2}{*}{ Protein modification targets } & Trypsin & AGT, FN1, GLUL, VIM, C3, A2M & 4.39E-03 \\
\hline & GST & VIM, FKBP1A, TALDO1, NSUN2 & $8.28 \mathrm{E}-03$ \\
\hline
\end{tabular}

Only three annotated genes/ESTs were identified in the telencephalon that were increased in response to D2 receptor agonists and decreased in response to D2 receptor blockage or DA depletion. This indicates that DA, acting through the D2 receptor, regulates these genes/ESTs. That relatively few genes affected by DA manipulation in the telencephalon was a surprising finding. While we expected tissue-specific responses to the various pharmacological treatments, we may have expected more than three genes to be affected in the Tel. In the case of D2 receptor, mRNA levels are high and specifically but widely expressed in regions of both Hyp and Tel of the African cichlid fish, Astatotilapia burtoni (O'Connell et al., 2011). However, it is not only the expression of receptors that will determine the response to an exogenous pharmacological agent, but also the ongoing effects of endogenous DA levels that are acting on both D1 and D2 receptors in vivo. It is clear in both goldfish and the cichlid, that DAergic innervation in the Hyp and Tel are extensive but clearly different, depending on the specific sub-region of each tissue (Hornby 


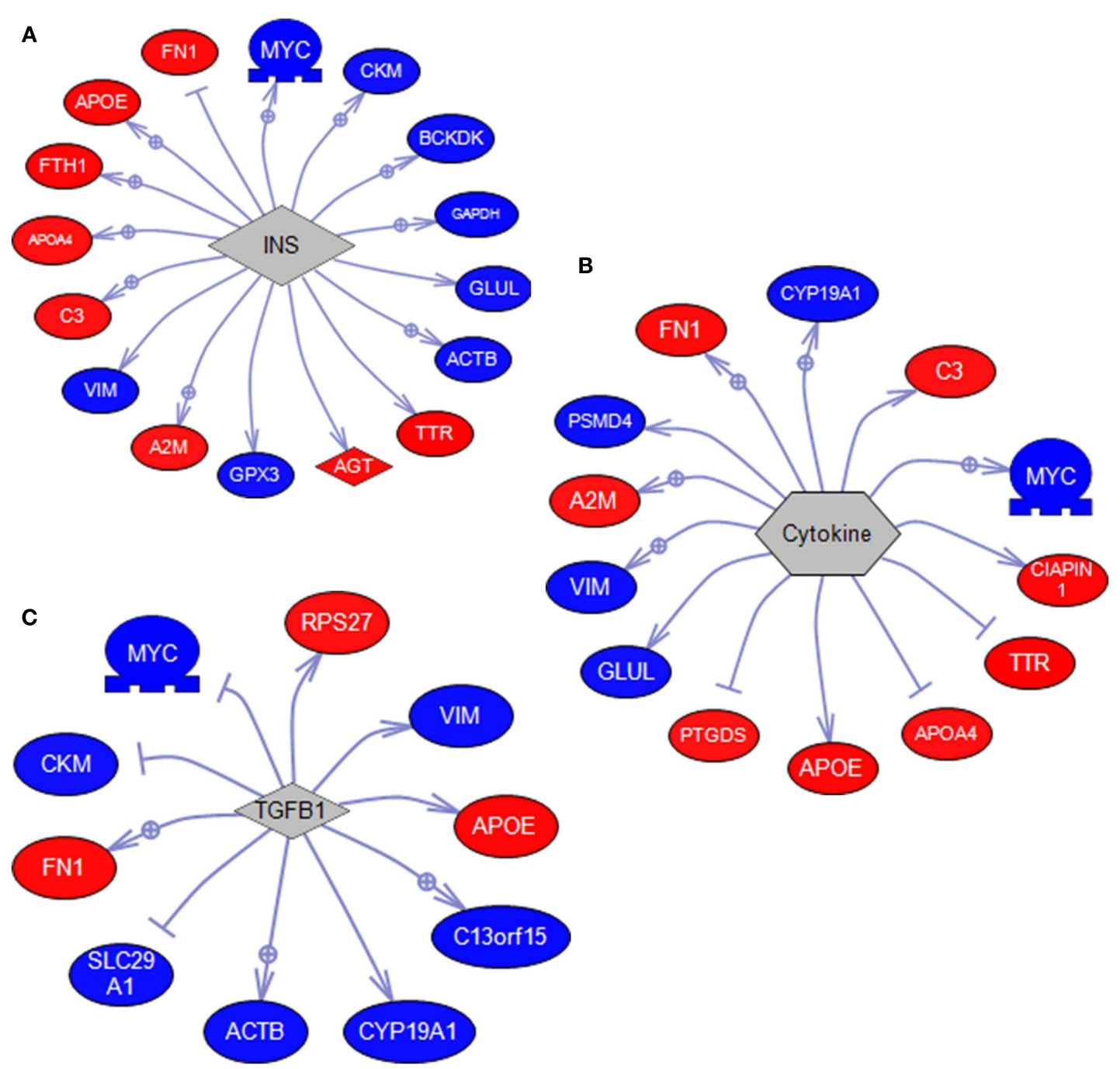

FIGURE 4 | SNEA diagrams showing the gene set target relationships for (A) insulin, (B) cytokines, and (C) TGF $\beta$ 1, represented by arrows. Arrows with a+ in a circle indicate a positive effect in addition to a relationship. Dead-head arrows (-|) indicate a negative effect in addition to a relationship. Directional changes of up (Red) and down (Blue) are color-coded. Results are shown relative to SKF 38393 with changes/color being opposite for MPTP $+\alpha$ MPT. Gene abbreviations are listed in Table 2. and Piekut, 1990; O'Connell et al., 2011). The clear difference in the global expression patterns in response to the various DA manipulations we report for goldfish Hyp and Tel supports this. Moreover, the type of cells expressing those receptors in each tissue will undoubtedly be different, so we do indeed expect major tissue differences.

Two of the DA-regulated genes/ESTs in the telencephalon are leucine-rich ppr-motif containing protein (LRPPRC) and solute carrier family 2 (facilitated glucose fructose transporter) member 5 (SLC2A5; glucose transporter 5; GLUT5). LRPPRC is a core nucleoid protein (Bogenhagen et al., 2008) and is hypothesized to have a regulatory role in the integration of the cytoskeleton with vesicular trafficking, nucleocytosolic shuttling, transcription, chromosome remodeling, and cytokinesis based on its interactions with other proteins by yeast 2-hybrid analysis (Liu and McKeehan, 2002). The third gene regulated by D2 in the telencephalon,
CCAAT/enhancer-binding protein beta $(\mathrm{C} / \mathrm{EBP} \beta)$, is particularly interesting. CaMKII phosphorylates C/EBP $\beta$ (Wegner et al., 1992), which, in turn, activates transcription factor-1 (ATF1; Shimomura et al., 1996), among other things. Methamphetamine administration to mice caused a dose-dependent increase in ATF1 and CREB DNA-binding activities (Lee et al., 2002). As CaMKII $\alpha$ protein levels were increased in response to DA agonists (Popesku et al., 2010), a working hypothesis of DAergic regulation of gene expression in the neuroendocrine brain of goldfish through the increase in ATF1 can thus be put forth.

Sub-network enrichment analysis takes advantage of previously characterized interactions between genes (expression relationships) and proteins (binding relationships). It is also able to associate genes and proteins with cell processes or diseases. The SNEA approach was developed by Ariadne (Pathway Studio $\left.^{\circledR}\right)$. Briefly, data on molecular interactions are retrieved from 
the ResNet nine database which is compiled using MedScan. The database contains over 20 million PubMed abstracts and approximately $900 \mathrm{~K}$ full-text articles (May 27, 2011). A background distribution of expression values in the gene list is calculated by an algorithm. This is followed by a statistical comparison between the sub-network and the background distribution using a MannWhitney $U$-Test, a $p$-value is generated that indicates the statistical significance of difference between two distributions (additional details can be found in the technical bulletin pg. 717 from Pathway Studio 7.0). SNEA has similar objectives to Ingenuity Pathway analysis and each is a useful tool to visualize molecular datasets. SNEA is different from KEGG which uses well defined biochemical and molecular pathways. SNEA has been applied in biomarker discovery in mammals (Kotelnikova et al., 2012) and for gene and protein networks in teleost fishes (Martyniuk et al., 2012; Trudeau et al., 2012). For this study, we chose to use Pathway Studios to visualize our data.

There were three major categories of the SNEA identified in the current study: cell signaling (STAT3, SP1, SMAD, Jun/Fos), immune response (IL-6, IL-1 $\beta$, and TNF, cytokine, NF- $\kappa$ B), and cell proliferation and growth (IGF1, TGF $\beta 1$ ). Inflammatory pathways modulated by DA have been characterized in mouse models and have been associated with degenerative processes and cytokines released from glial cells play important roles in mediating cellular responses to injury due to neurotoxicants such as MPTP. For example, old male and female transgenic mice injected intraperitoneally with MPTP $(15 \mathrm{mg} / \mathrm{kg}$ for 2 days at two injections/day) caused males to have dramatic increases in IL-1 $\beta$ luciferase reporter gene activity that correlated to the increased susceptibility of dopaminergic neurons to MPTP toxicity found in old male mice (Bian et al., 2009). In the same study, mRNA levels of TNF- $\alpha$ and IL- 6 were not changed, but notable here is that genes affected downstream of IL- 6 and TNF signaling were altered by DA in the goldfish hypothalamus, suggesting that these signaling cascades can be sensitive to dopaminergic inputs. In support of these data, both mRNA and protein levels for various cytokines (IL-1 $\beta$, TNF- $\alpha$, and IL-6) and expression of their receptors were significantly increased in the substantia nigra of MPTP-treated mice (Lofrumento et al., 2011). Here we identify putative gene targets and subsequent genomic effects that may occur after cytokine induction in the vertebrate CNS. A recent review by O'Callaghan et al. (2008) discuss the role of MPTP in inflammation in relation to cytokine signaling, including cytokines identified in the goldfish hypothalamus such as IL-1 $\beta$ and IL-6. Lastly, in regards to the inflammatory response in the goldfish, many of the cell signaling cascades are also involved in the immune response. For example, JAK/STAT3 signaling plays a role in inflammation in the mammalian brain in response to MPTP (Sriram et al., 2004). Therefore, the gene set node for cell signaling molecules (e.g., STAT) identified in the goldfish may directly stimulate inductions in cytokines.

Gene targets of IGF1 and TGF $\beta$ were also affected in expression after DA depletion and DA agonism. IGF1 activates RAS, P13K, and AKT signaling pathway to stimulate growth and differentiation of cells. TGF- $\beta$ is a member of the transforming growth factor family that is involved in cell differentiation and regulation of the immune system. Both these signaling pathways are known to have a role in dopaminergic signaling and to be associated with the onset of neurodegenerative diseases. There are reports to suggest that IGF signaling may be involved in neuroprotection within the CNS. IGF1 has been shown to have protective role in MPP + induced neurotoxicity in human neuroblastoma SH-EP1 cells by inhibiting apoptotic processes (Wang et al., 2010) and female rats treated with the neurotoxin 6-hydroxydopamine (6-OHDA) did not show reduced tyrosine hydroxylase immunoreactivity (a marker for DA toxicity) after intracerebroventricular infusion of IGF1 substantia nigra compared to those without the treatment (Quesada et al., 2008). The effect of IGF1 was dependent upon the PI3K/Akt pathway. It is plausible that gene expression changes in the goldfish hypothalamus in response to DA depletion and DA receptor activation are protective responses to DA-mediated neurotoxicity. Tong et al. (2009) investigated IGF distribution in human post-mortem brain tissues and report that IGF-I expression was significantly elevated in the frontal cortex of Parkinson's patients while IGF-II expression was significantly reduced in the frontal white matter of PD patients. Thus, there are complex interactions between different IGF signaling pathways in the neurodegenerative brain (IGF1 and IGF2), however experimental evidence associates IGF in these processes. Similar to IGF1, TGF $\beta$ signaling targets are implemented in DA signaling in the goldfish hypothalamus. This pathway has also been implicated in neurodegeneration (Andrews et al., 2006) and the TGF $\beta$ signaling pathway can be modulated with DA treatments (Recouvreux et al., 2011).

Fish models are increasingly being used for investigations into the mechanisms of disease occurrence and progression (Weinreb and Youdim, 2007). Here we provide examples and demonstrate the usefulness of implementing SNEA to gain increased insight into key regulators underlying neurotransmitter signaling in the neuroendocrine brain and uncover novel associations between disease states and pharmacological treatments. In so doing, we provide a foundation for future work on dopaminergic regulation of gene expression in fish.

\section{AUTHORS' CONTRIBUTIONS}

Jason T. Popesku conceived of the study, designed and carried out the experiments, analyzed the data, and drafted the manuscript. Christopher J. Martyniuk participated in the design of the experiments, performed the sub-network enrichment analysis, and helped draft the manuscript. Vance L. Trudeau helped conceive the individual experiments, participated in the design and coordination of the study, and helped to draft the manuscript. All authors read and approved the final manuscript.

\section{ACKNOWLEDGMENTS}

The authors would like to thank B. McNeill and S. F. Perry for performing the HPLC analysis. Jason T. Popesku and Vance L. Trudeau would like to thank the Parkinson's Research Consortium of Ottawa for financial support. Jason T. Popesku appreciates the support of the Ontario Graduate Scholarship. This research was funded by NSERC Discovery Grants to Vance L. Trudeau and Christopher J. Martyniuk, and a Canadian Research Chair (Christopher J. Martyniuk). 


\section{REFERENCES}

Adams, D. S., Kiyokawa, M., Getman, M. E., and Shashoua, V. E. (1996). Genes encoding giant danio and golden shiner ependymin. Neurochem. Res. 21, 377-384.

Adams, D. S., and Shashoua, V. E. (1994). Cloning and sequencing the genes encoding goldfish and carp ependymin. Gene 141, 237-241.

Andrews, Z. B., Zhao, H., Frugier, T., Meguro, R., Grattan, D. R., Koishi, K., et al. (2006). Transforming growth factor beta2 haploinsufficient mice develop age-related nigrostriatal dopamine deficits. Neurobiol. Dis. 21, 568-575.

Anglade, I., Zandbergen, T., and Kah, O. (1993). Origin of the pituitary innervation in the goldfish. Cell Tissue Res. 273, 345-355.

Baik, J. H., Picetti, R., Saiardi, A., Thiriet, G., Dierich, A., Depaulis, A., et al. (1995). Parkinsonian-like locomotor impairment in mice lacking dopamine D2 receptors. Nature 377, 424-428.

Baillien, M., and Balthazart, J. (1997). A direct dopaminergic control of aromatase activity in the quail preoptic area. J. Steroid Biochem. Mol. Biol. 63, 99-113.

Bian, M. J., Li, L. M., Yu, M., Fei, J., and Huang, F. (2009). Elevated interleukin-1beta induced by 1-methyl-4-phenyl-1,2,3,6tetrahydropyridine aggravating dopaminergic neurodegeneration in old male mice. Brain Res. 1302, 256-264.

Bogenhagen, D. F., Rousseau, D., and Burke, S. (2008). The layered structure of human mitochondrial DNA nucleoids. J. Biol. Chem. 283, 3665-3675.

Chen, H. J., Huang, D. J., Hou, W. C., Liu, J. S., and Lin, Y. H. (2006). Molecular cloning and characterization of a granulin-containing cysteine protease SPCP3 from sweet potato (Ipomoea batatas) senescent leaves. J. Plant Physiol. 163, 863-876.

Chen, J. Y., Chen, J. C., and Wu, J. L. (2003). Molecular cloning and functional analysis of zebrafish highdensity lipoprotein-binding protein. Comp. Biochem. Physiol. B Biochem. Mol. Biol. 136, 117-130.

Chen, M. H., Li, Y. H., Chang, Y., Hu, S. Y., Gong, H. Y., Lin, G. H., et al. (2007). Co-induction of hepatic IGF-I and progranulin mRNA by growth hormone in tilapia, Oreochromis mossambiccus. Gen. Comp. Endocrinol. 150, 212-218.

Chiba, S., Suzuki, M., Yamanouchi, K., and Nishihara, M. (2007). Involvement of granulin in estrogen-induced neurogenesis in the adult rat hippocampus. J. Reprod. Dev. 53, 297-307.

Chuang, H. Y., Lee, E., Liu, Y. T., Lee, D., and Ideker, T. (2007). Networkbased classification of breast cancer metastasis. Mol. Syst. Biol. 3, 140.

Churchill, G. A. (2002). Fundamentals of experimental design for cDNA microarrays. Nat. Genet. 32(Suppl. 4), 90-95

Clint, S. C., and Zupanc, G. K. (2002). Up-regulation of vimentin expression during regeneration in the adult fish brain. Neuroreport 13, 317-320. Cornil, C. A., Seutin, V., Motte, P., and Balthazart, J. (2004). Electrophysiological and neurochemical characterization of neurons of the medial preoptic area in Japanese quail (Coturnix japonica). Brain Res. 1029, 224-240.

Diotel, N., Le Page, Y., Mouriec, K., Tong, S. K., Pellegrini, E., Vaillant, C., et al. (2010). Aromatase in the brain of teleost fish: expression, regulation and putative functions. Front. Neuroendocrinol. 31, 172-192.

Dufour, S., Sebert, M. E., Weltzien, F. A., Rousseau, K., and Pasqualini, C. (2010). Neuroendocrine control by dopamine of teleost reproduction. $J$. Fish Biol. 76, 129-160.

Dufour, S., Weltzien, F. A., Sebert, M. E., LeBelle, N., Vidal, B., Vernier, P. et al. (2005). Dopaminergic inhibition of reproduction in teleost fishes: ecophysiological and evolutionary implications. Ann. N. Y. Acad. Sci. 1040, 9-21.

Episkopou, V., Maeda, S., Nishiguchi, S., Shimada, K., Gaitanaris, G. A. Gottesman, M. E., et al. (1993). Disruption of the transthyretin gene results in mice with depressed levels of plasma retinol and thyroid hormone. Proc. Natl. Acad. Sci. U.S.A. 90, 2375-2379.

Glasgow, E., Druger, R. K., Fuchs, C., Levine, E. M., Giordano, S., and Schechter, N. (1994). Cloning of multiple forms of goldfish vimentin: differential expression in CNS. J. Neurochem. 63, 470-481.

Hanington, P. C., Barreda, D. R., and Belosevic, M. (2006). A novel hematopoietic granulin induces proliferation of goldfish (Carassius auratus L.) macrophages. J. Biol. Chem. 281, 9963-9970.

Hibbert, B., Fung, I., McAuley, R., Lariviere, K., MacNeil, B., BafiYeboa, N., et al. (2004). Increased GAD67 mRNA levels are correlated with in vivo GABA synthesis in the MPTP-treated catecholaminedepleted goldfish brain. Mol. Brain Res. 128, 121-130.
Hibbert, B., Fung, I., McAuley, R., Samia, M., and Trudeau, V. (2005). Catecholamine depletion modulates serum LH levels, GAD67 mRNA, and GABA synthesis in the goldfish. Gen. Comp. Endocrinol. 140, 176-183.

Hong, S. J., and Kang, K. W. (1999). Purification of granulin-like polypeptide from the blood-sucking leech, Hirudo nipponia. Protein Expr. Purif. 16, 340-346.

Hornby, P. J., and Piekut, D. T. (1990) Distribution of catecholaminesynthesizing enzymes in goldfish brains: presumptive dopamine and norepinephrine neuronal organization. Brain Behav. Evol. 35, 49-64.

Jalabert, B. (2005). Particularities of reproduction and oogenesis in teleost fish compared to mammals. Reprod. Nutr. Dev. 45, 261-279.

Kang, B. J., Jung, J. H., Lee, J. M., Lim, S. G., Saito, H., Kim, M. H., et al. (2007). Structural and expression analyses of two vitellogenin genes in the carp, Cyprinus carpio. Comp. Biochem. Physiol. B Biochem. Mol. Biol. 148, 445-453.

Kauer, J. A., and Malenka, R. C. (2007). Synaptic plasticity and addiction. Nat. Rev. Neurosci. 8, 844-858.

Kotelnikova, E., Shkrob, M. A., Pyatnitskiy, M. A., Ferlini, A., and Daraselia, N. (2012). Novel approach to metaanalysis of microarray datasets reveals muscle remodeling-related drug targets and biomarkers in Duchenne muscular dystrophy. PLoS Comput. Biol. 8, e1002365. doi:10.1371/journal.pcbi.1002365

Kumakura, N., Okuzawa, K., Gen, K., and Kagawa, H. (2003). Effects of gonadotropin-releasing hormone agonist and dopamine antagonist on hypothalamus-pituitary-gonadal axis of pre-pubertal female red seabream (Pagrus major). Gen. Comp. Endocrinol. 131, 264-273.

Le Page, Y., Diotel, N., Vaillant, C., Pellegrini, E., Anglade, I., Merot, Y. et al. (2010). Aromatase, brain sexualization and plasticity: the fish paradigm. Eur. J. Neurosci. 32, 2105-2115.

Lee, Y. W., Son, K. W., Flora, G., Hennig, B., Nath, A., and Toborek, M. (2002). Methamphetamine activates DNA binding of specific redox-responsive transcription factors in mouse brain. J. Neurosci. Res. 70, 82-89.

Levavi-Sivan, B., Safarian, H., Rosenfeld, H., Elizur, A., and Avitan, A. (2004). Regulation of gonadotropin-releasing hormone (GnRH)-receptor gene expression in tilapia: effect of $\mathrm{GnRH}$ and dopamine. Biol. Reprod. 70, 1545-1551.

Linard, B., Anglade, I., Corio, M., Navas, J. M., Pakdel, F., Saligaut, C., et al. (1996). Estrogen receptors are expressed in a subset of tyrosine hydroxylase-positive neurons of the anterior preoptic region in the rainbow trout. Neuroendocrinology 63, 156-165.

Liu, L., and McKeehan, W. L. (2002). Sequence analysis of LRPPRC and its SEC1 domain interaction partners suggests roles in cytoskeletal organization, vesicular trafficking, nucleocytosolic shuttling, and chromosome activity. Genomics 79, 124-136.

Lofrumento, D. D., Saponaro, C., Cianciulli, A., De Nuccio, F., Mitolo, V., Nicolardi, G., et al. (2011). MPTP-induced neuroinflammation increases the expression of proinflammatory cytokines and their receptors in mouse brain. Neuroimmunomodulation 18, 79-88.

Marlatt, V. L., Martyniuk, C. J., Zhang, D., Xiong, H., Watt, J., Xia, X., et al. (2008). Auto-regulation of estrogen receptor subtypes and gene expression profiling of 17beta-estradiol action in the neuroendocrine axis of male goldfish. Mol. Cell. Endocrinol. 283, 38-48.

Marsh, K. E., Creutz, L. M., Hawkins, M. B., and Godwin, J. (2006). Aromatase immunoreactivity in the bluehead wrasse brain, Thalassoma bifasciatum: immunolocalization and coregionalization with arginine vasotocin and tyrosine hydroxylase. Brain Res. 1126, 91-101.

Martyniuk, C. J., Alvarez, S., Lo, B. P., Elphick, J. R., and Marlatt, V. L. (2012). Hepatic protein expression networks associated with masculinization in the female fathead minnow (Pimephales promelas). J. Proteome Res. 11, 4147-4161.

Martyniuk, C. J., Chang, J. P., and Trudeau, V. L. (2007). The effects of GABA agonists on glutamic acid decarboxylase, GABA-transaminase, activin, salmon gonadotrophinreleasing hormone and tyrosine hydroxylase mRNA in the goldfish (Carassius auratus) neuroendocrine brain. J. Neuroendocrinol. 19, 390-396.

Martyniuk, C. J., Feswick, A., Spade, D. J., Kroll, K. J., Barber, D. S., and Denslow, N. D. (2010). Effects of acute dieldrin exposure on neurotransmitters and global gene transcription in largemouth bass (Micropterus salmoides) hypothalamus. Neurotoxicology 31, 356-366. 
Martyniuk, C. J., Xiong, H., Crump, K., Chiu, S., Sardana, R., Nadler, A., et al. (2006). Gene expression profiling in the neuroendocrine brain of male goldfish (Carassius auratus) exposed to 17alpha-ethinylestradiol. Physiol. Genomics 27, 328-336.

Mennigen, J. A., Martyniuk, C. J., Crump, K., Xiong, H., Zhao, E., Popesku, J., et al. (2008). Effects of fluoxetine on the reproductive axis of female goldfish (Carassius auratus). Physiol. Genomics 35, 273-282.

Moestrup, S. K., and Kozyraki, R. (2000). Cubilin, a high-density lipoprotein receptor. Curr. Opin. Lipidol. 11, 133-140.

Moon, Y. A., and Horton, J. D. (2003). Identification of two mammalian reductases involved in the twocarbon fatty acyl elongation cascade. J. Biol. Chem. 278, 7335-7343.

Mortensen, A. S., and Arukwe, A. (2006). Dimethyl sulfoxide is a potent modulator of estrogen receptor isoforms and xenoestrogen biomarker responses in primary culture of salmon hepatocytes. Aquat. Toxicol. 79, 99-103.

Nishimura, M., Nikawa, T., Kawano, Y., Nakayama, M., and Ikeda, M. (2008). Effects of dimethyl sulfoxide and dexamethasone on mRNA expression of housekeeping genes in cultures of $\mathrm{C} 2 \mathrm{C} 12$ myotubes. Biochem. Biophys. Res. Commun. 367, 603-608.

O'Callaghan, J. P., Sriram, K., and Miller, D. B. (2008). Defining "neuroinflammation.” Ann. N. Y. Acad. Sci. 1139, 318-330.

O'Connell, L. A., Fontenot, M. R., and Hofmann, H. A. (2011). Characterization of the dopaminergic system in the brain of an African cichlid fish, Astatotilapia burtoni. J. Comp. Neurol. 519, 75-92.

Omeljaniuk, R. J., Shih, S. H., Peter, R. E. (1987). In-vivo evaluation of dopamine receptor-mediated inhibition of gonadotrophin secretion from the pituitary gland of the goldfish, Carassius auratus. J. Endocrinol. 114, 449-458.

Otto, C. J., Lin, X., and Peter, R. E. (1999). Dopaminergic regulation of three somatostatin mRNAs in goldfish brain. Regul. Pept. 83, 97-104.

Perkins, E. J., Chipman, J. K., Edwards, S., Habib, T., Falciani, F., Taylor, R., et al. (2011). Reverse engineering adverse outcome pathways. Environ. Toxicol. Chem. 30, 22-38.

Peter, R. E., Chang, J. P., Nahorniak, C. S., Omeljaniuk, R. J., Sokolowska, M., Shih, S., et al.
(1986). Interactions of catecholamines and $\mathrm{GnRH}$ in regulation of gonadotropin secretion in teleost fish. Recent Prog. Horm. Res. 42, 513-548.

Poli, A., Gandolfi, O., Lucchi, R., and Barnabei, O. (1992). Spontaneous recovery of MPTP-damaged catecholamine systems in goldfish brain areas. Brain Res. 585, 128-134.

Pollard, H. B., Dhariwal, K., Adeyemo, O. M., Markey, C. J., Caohuy, H., Levine, M., et al. (1992). A Parkinsonian syndrome induced in the goldfish by the neurotoxin MPTP. FASEB J. 6, 3108-3116.

Popesku, J. T., Martyniuk, C. J., Denslow, N. D., and Trudeau, V. L. (2010). Rapid dopaminergic modulation of the fish hypothalamic transcriptome and proteome. PLoS ONE 5, e12338. doi:10.1371/journal.pone.0012338

Popesku, J. T., Martyniuk, C. J., Mennigen, J., Xiong, H., Zhang, D., Xia, X., et al. (2008). The goldfish (Carassius auratus) as a model for neuroendocrine signaling. Mol. Cell. Endocrinol. 293, 43-56.

Popesku, J. T., Mennigen, J. A., Chang, J. P., and Trudeau, V. L. (2011a). Dopamine D1 receptor blockage potentiates AMPA-stimulated luteinising hormone release in the goldfish. J. Neuroendocrinol. 23, 302-309.

Popesku, J. T., Navarro-Martin, L., and Trudeau, V. L. (2011b). Evidence for alternative splicing of a dopamine D2 receptor in a teleost. Physiol. Biochem. Zool. 84, 135-146.

Query, C. C. (2009). Structural biology: spliceosome subunit revealed. Nature 458, 418-419.

Quesada, A., Lee, B. Y., and Micevych, P. E. (2008). PI3 kinase/Akt activation mediates estrogen and IGF1 nigral DA neuronal neuroprotection against a unilateral rat model of Parkinson's disease. Dev. Neurobiol. 68, 632-644.

Ravindra, R., and Grosvenor, C. E. (1988). Soluble and polymerized tubulin levels in the anterior pituitary lobe of the lactating rat during suckling. Endocrinology 122, 114-119.

Ravindra, R., and Grosvenor, C. E. (1990). Involvement of cytoskeleton in polypeptide hormone secretion from the anterior pituitary lobe: a review. Mol. Cell. Endocrinol. 71, 165-176.

Recouvreux, M. V., Guida, M. C., Rifkin, D. B., Becu-Villalobos, D., and Diaz-Torga, G. (2011). Active and total transforming growth factor-\{beta 1 are differentially regulated by dopamine and estradiol in the pituitary. Endocrinology 152 2722-2730.

Rite, I., Arguelles, S., Venero, J. L., Garcia-Rodriguez, S., Ayala, A., Cano, J., et al. (2007). Proteomic identification of biomarkers in the cerebrospinal fluid in a rat model of nigrostriatal dopaminergic degeneration. J. Neurosci. Res. 85, 3607-3618.

Salgado-Garrido, J., Bragado-Nilsson, E., Kandels-Lewis, S., and Seraphin, B. (1999). Sm and Sm-like proteins assemble in two related complexes of deep evolutionary origin. EMBO J. 18, 3451-3462.

Seeman, P., and Kapur, S. (2000). Schizophrenia: more dopamine, more D2 receptors. Proc. Natl. Acad. Sci. U.S.A. 97, 7673-7675.

Shashoua, V. E. (1991). Ependymin, a brain extracellular glycoprotein, and CNS plasticity. Ann. N. Y. Acad. Sci. 627, 94-114.

Shashoua, V. E., Adams, D., and BoyerBoiteau, A. (2001). CMX-8933, a peptide fragment of the glycoprotein ependymin, promotes activation of AP-1 transcription factor in mouse neuroblastoma and rat cortical cell cultures. Neurosci. Lett. 312 , 103-107.

Shimomura, A., Ogawa, Y., Kitani, T., Fujisawa, H., and Hagiwara, M. (1996). Calmodulin-dependent protein kinase II potentiates transcriptional activation through activating transcription factor 1 but not cAMP response elementbinding protein. J. Biol. Chem. 271, 17957-17960.

Sivachenko, A. Y., Yuryev, A., Daraselia, N., and Mazo, I. (2007). Molecular networks in microarray analysis. J. Bioinform. Comput. Biol. 5, 429-456.

Soccio, R. E., Adams, R. M. Romanowski, M. J., Sehayek, E., Burley, S. K., and Breslow, J. L. (2002). The cholesterolregulated StarD4 gene encodes a StAR-related lipid transfer protein with two closely related homologues, StarD5 and StarD6. Proc. Natl. Acad. Sci. U.S.A. 99, 6943-6948.

Sriram, K., Benkovic, S. A., Hebert, M. A., Miller, D. B., and O'Callaghan, J. P. (2004). Induction of gp130related cytokines and activation of JAK2/STAT3 pathway in astrocytes precedes up-regulation of glial fibrillary acidic protein in the 1-methyl-4-phenyl-1,2,3,6tetrahydropyridine model of neurodegeneration: key signaling pathway for astrogliosis in vivo? J. Biol. Chem. 279, 19936-19947.

Stoffel-Wagner, B. (2003). Neurosteroid biosynthesis in the human brain and its clinical implications. Ann. N. Y. Acad. Sci. 1007, 64-78.

Suarez-Castillo, E. C., and GarciaArraras, J. E. (2007). Molecular evolution of the ependymin protein family: a necessary update. $B M C$ Evol. Biol. 7, 23. doi:10.1186/14712148-7-23

Suarez-Castillo, E. C., Medina-Ortiz, W. E., Roig-Lopez, J. L., and GarciaArraras, J. E. (2004). Ependymin, a gene involved in regeneration and neuroplasticity in vertebrates, is overexpressed during regeneration in the echinoderm Holothuria glaberrima. Gene 334, 133-143.

Sugawara, T., Fujimoto, Y., and Ishibashi, T. (2001). Molecular cloning and structural analysis of human sterol C5 desaturase. Biochim. Biophys. Acta 1533, 277-284.

Suzuki, M., Yonezawa, T., Fujioka, H., Matuamuro, M., and Nishihara, M. (2001). Induction of granulin precursor gene expression by estrogen treatment in neonatal rat hypothalamus. Neurosci. Lett. 297, 199-202.

Tong, M., Dong, M., and de la Monte, S. M. (2009). Brain insulin-like growth factor and neurotrophin resistance in Parkinson's disease and dementia with Lewy bodies: potential role of manganese neurotoxicity. $J$. Alzheimers Dis. 16, 585-599.

Trudeau, V. L., Martyniuk, C. J., Zhao, E., Hu, H., Volkoff, H., Decatur, W. A., et al. (2012). Is secretoneurin a new hormone? Gen. Comp. Endocrinol. 175, 10-18.

Trudeau, V. L., Sloley, B. D., Wong, A. O., and Peter, R. E. (1993). Interactions of gonadal steroids with brain dopamine and gonadotropinreleasing hormone in the control of gonadotropin-II secretion in the goldfish. Gen. Comp. Endocrinol. 89, 39-50.

Tusher, V. G., Tibshirani, R., and Chu, G. (2001). Significance analysis of microarrays applied to the ionizing radiation response. Proc. Natl. Acad. Sci. U.S.A. 98, 5116-5121.

Vacher, C., Ferriere, F., Marmignon, M. H., Pellegrini, E., and Saligaut, C. (2002). Dopamine D2 receptors and secretion of FSH and LH: role of sexual steroids on the pituitary of the female rainbow trout. Gen. Comp. Endocrinol. 127, 198-206.

Wang, L., Yang, H. J., Xia, Y. Y., and Feng, Z. W. (2010). Insulin-like growth 
factor 1 protects human neuroblastoma cells SH-EP1 against MPP+induced apoptosis by AKT/GSK3beta/JNK signaling. Apoptosis 15, 1470-1479.

Wegner, M., Cao, Z., and Rosenfeld, M. G. (1992). Calcium-regulated phosphorylation within the leucine zipper of C/EBP beta. Science 256, 370-373.

Weinreb, O., and Youdim, M. B. (2007). A model of MPTP-induced Parkinson's disease in the goldfish. Nat. Protoc. 2, 3016-3021.

Wiens, S. C. (2009). Thyroid Hormone Regulation of the Reproductive Neuroendocrine Axis of the Goldfish (Carassius auratus), Department of Biology, University of Ottawa, Ottawa, 180.

Williams, D. R., Li, W., Hughes, M. A., Gonzalez, S. F., Vernon, C., Vidal, M. C., et al. (2008). Genomic resources and microarrays for the common carp Cyprinus carpio L. J. Fish Biol. 72, 2095-2117.

Wong, A. O., Chang, J. P., and Peter, R. E. (1992). Dopamine stimulates growth hormone release from the pituitary of goldfish, Carassius auratus, through the dopamine D1 receptors. Endocrinology 130, 1201-1210.

Woodward, J. J. (1982). Plasma catecholamines in resting rainbow trout, Salmo gairdneri Richardson, by high pressure liquid chromatography. $J$. Fish Biol. 21, 429-432.

Xiong, H., Zhang, D., Martyniuk, C. J., Trudeau, V. L., and Xia, X. (2008). Using generalized procrustes analysis (GPA) for normalization of cDNA microarray data. BMC Bioinformatics 9, 25. doi:10.1186/14712105-9-25

Yu, K. L., and Peter, R. E. (1992). Adrenergic and dopaminergic regulation of gonadotropin-releasing hormone release from goldfish preoptic-anterior hypothalamus and pituitary in vitro. Gen. Comp. Endocrinol. 85, 138-146.

Zhang, D., Popesku, J. T., Martyniuk, C. J., Xiong, H., Duarte-Guterman, P., Yao, L., et al. (2009a). Profiling neuroendocrine gene expression changes following fadrozoleinduced estrogen decline in the female goldfish. Physiol. Genomics 38, 351-361.

Zhang, D., Xiong, H., Mennigen, J. A., Popesku, J. T., Marlatt, V. L., Martyniuk, C. J., et al. (2009b). Defining global neuroendocrine gene expression patterns associated with reproductive seasonality in fish. PLoS ONE 4, e5816. doi:10.1371/journal.pone.0005816

Conflict of Interest Statement: The authors declare that the research was conducted in the absence of any commercial or financial relationships that could be construed as a potential conflict of interest.

Received: 04 August 2012; accepted: 12 October 2012; published online: 02 November 2012.

Citation: Popesku JT, Martyniuk CJ and Trudeau VL (2012) Meta-type analysis of dopaminergic effects on gene expression in the neuroendocrine brain of female goldfish. Front. Endocrin. 3:130. doi: 10.3389/fendo.2012.00130

This article was submitted to Frontiers in Experimental Endocrinology, a specialty of Frontiers in Endocrinology.

Copyright (c) 2012 Popesku, Martyniuk and Trudeau. This is an open-access article distributed under the terms of the Creative Commons Attribution License, which permits use, distribution and reproduction in other forums, provided the original authors and source are credited and subject to any copyright notices concerning any third-party graphics etc. 


\section{APPENDIX}

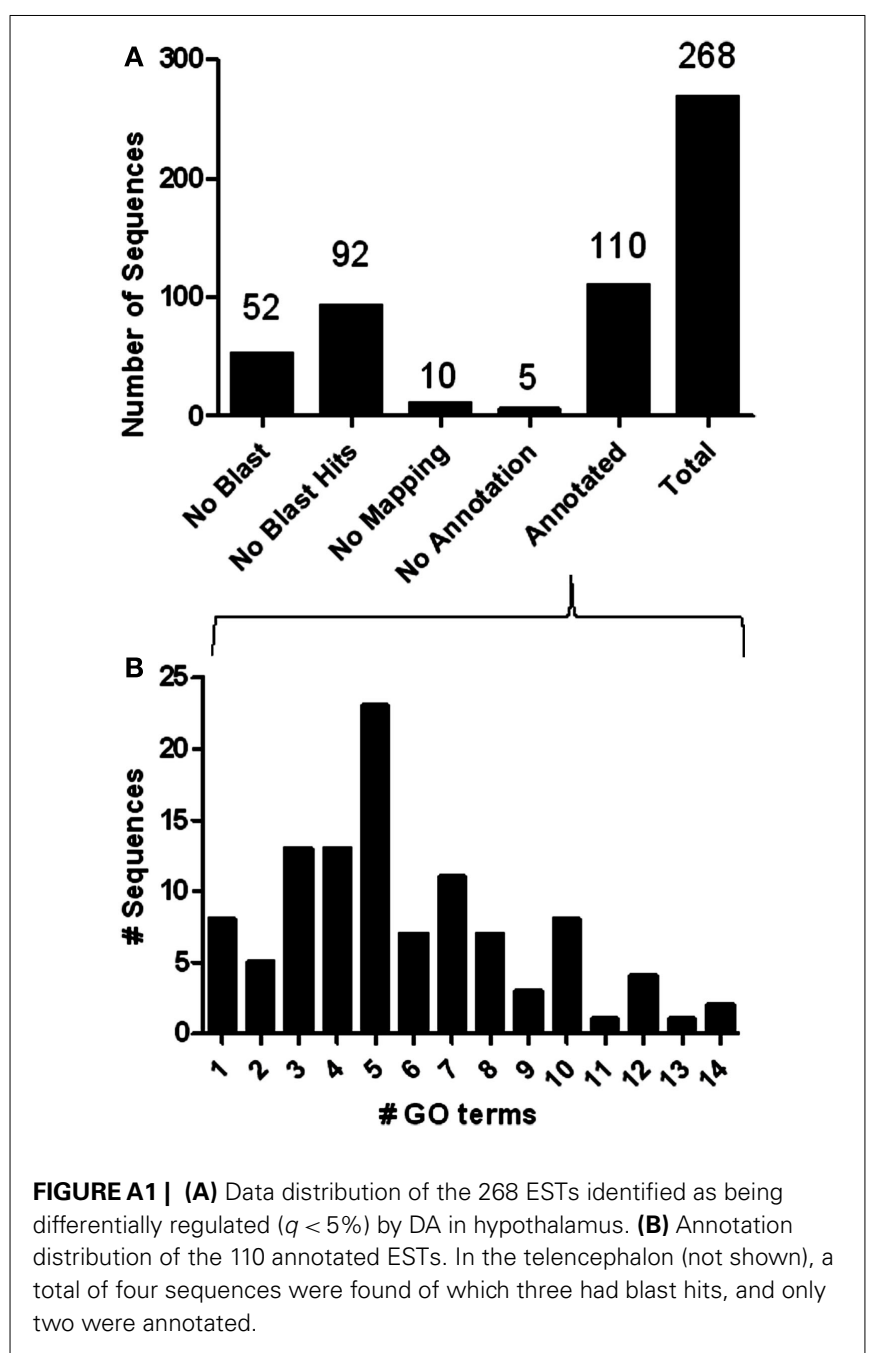


Table A1 | ESTs were manually selected based on identical AURATUS GenelDs and on the basis of differential regulation in opposite directions for MPTP or the antagonists vs. agonists, or in the same direction for MPTP vs. antagonists.

\begin{tabular}{|c|c|c|c|c|c|c|c|c|}
\hline \multirow[t]{2}{*}{ Tissue } & \multirow{2}{*}{$\begin{array}{l}\text { AURATUS } \\
\text { ID }\end{array}$} & \multirow[t]{2}{*}{ Best blast hit } & \multicolumn{3}{|c|}{ DA depletion or receptor blockage } & \multicolumn{2}{|c|}{ DA mimic } & \multirow[t]{2}{*}{ Accession } \\
\hline & & & $\begin{array}{l}\text { MPTP + } \\
\text { aMPT }\end{array}$ & SCH 23390 & Sulpiride & SKF 38393 & LY171555 & \\
\hline Hyp & $08 \mathrm{j} 13$ & 14 kDa Apolipoprotein & -1.5 & & & 1.7 & & CF662566 \\
\hline Hyp & 08b22 & $\begin{array}{l}\text { 17-Beta hydroxysteroid dehydrogenase type } \\
\text { 12B, 3-ketoacyl-CoA reductase type B }\end{array}$ & 1.4 & & & -1.7 & & CA968619 \\
\hline Hyp & $08 \mathrm{e} 14$ & 40S Ribosomal protein S27 & -1.5 & & & 1.7 & & CA968660 \\
\hline Hyp & $07 f 01$ & Abhydrolase domain containing 12 & -1.6 & & & 1.8 & & CA967283 \\
\hline Hyp & $22 n 08$ & Adenylate kinase 3-like 1 & 1.3 & & & -1.5 & & CA969490 \\
\hline Hyp & 08k20 & Aldehyde dehydrogenase 7 family, member $\mathrm{A} 1$ & -1.3 & & & & 1.3 & CA968758 \\
\hline Hyp & $03 \mathrm{~h} 23$ & Aldolase C & 1.4 & & & -1.6 & & DY231930 \\
\hline Hyp & $16 n 14$ & Apolipoprotein e & -1.3 & & & 2.4 & & CF662778 \\
\hline Hyp & 04a17 & Aromatase b & 1.3 & & & -1.7 & & FG392770 \\
\hline Hyp & $14 \mathrm{k} 14$ & arp2 Actin-related protein 2 homolog & -1.3 & & & 2.3 & 1.3 & CA964468 \\
\hline Hyp & $12 \mid 13$ & $\begin{array}{l}\text { asf1 Anti-silencing function } 1 \text { homolog b } \\
\text { (cerevisiae) }\end{array}$ & -1.3 & & & 1.9 & & CA966040 \\
\hline Hyp & 16115 & atp-Binding sub-family f member 2 & -1.3 & & & 1.6 & & CA966450 \\
\hline Hyp & 16014 & BC-10 protein & -1.3 & & & 1.9 & & CA966992 \\
\hline Hyp & 03022 & Beta-actin & 1.3 & & & -1.6 & & DY232011 \\
\hline Hyp & 22124 & Branched chain ketoacid dehydrogenase kinase & & 1.6 & & -1.8 & & CA969461 \\
\hline Hyp & $02 \mathrm{a} 23$ & Calmodulin $1 \mathrm{~b}$ & 1.2 & & & -1.7 & & FG392553 \\
\hline Hyp & 08015 & Complement $\mathrm{C} 3-\mathrm{H} 2$ & -1.4 & & & 1.6 & & CA970421 \\
\hline Hyp & 08b20 & Complement component q subcomponent-like 4 & -1.3 & & & & 1.3 & CA968617 \\
\hline Hyp & 02c23 & Creatine kinase b variant 1 & 1.3 & & & -1.6 & & DY231608 \\
\hline Hyp & $02 n 10$ & Creatine testis isozyme & 1.2 & & & -1.5 & & DY231690 \\
\hline Hyp & 21119 & C-type lectin & 1.5 & -1.7 & & -1.7 & & CA969207 \\
\hline Hyp & $19 a 14$ & Cubilin (intrinsic factor-cobalamin receptor) & -1.4 & & & 1.4 & & CA964997 \\
\hline Hyp & $17 g 09$ & cxxc Finger 1 (phd domain) & 1.3 & & & -1.7 & & CA964951 \\
\hline Hyp & $11 \mathrm{i} 01$ & $\begin{array}{l}\text { Cyprinus carpio DN1 mRNA for DNase I, } \\
\text { complete cds }\end{array}$ & -1.4 & & & 1.7 & & CA965953 \\
\hline Hyp & $06 \mathrm{~d} 13$ & Cytochrome p450 like & -1.4 & & & & 1.6 & CA965416 \\
\hline Hyp & 05101 & Cytokine induced apoptosis inhibitor 1 & -1.4 & & & 2.3 & & CA966987 \\
\hline Hyp & $\log 12$ & $\begin{array}{l}\text { Danio rerio HECT domain containing } 1 \text { (hectd1), } \\
\text { mRNA }\end{array}$ & 1.5 & & & -1.5 & & CA967652 \\
\hline Hyp & $19 \mathrm{~h} 04$ & $\begin{array}{l}\text { Danio rerio heterogeneous nuclear } \\
\text { ribonucleoprotein A/B, mRNA (cDNA clone } \\
\text { MGC:55953), complete cds }\end{array}$ & & -1.4 & & 1.8 & & CA965823 \\
\hline Hyp & $24 j 13$ & $\begin{array}{l}\text { Danio rerio lin-7 homolog A (C. elegans; lin7a), } \\
\text { mRNA }\end{array}$ & -1.4 & & & & 1.4 & CA969901 \\
\hline
\end{tabular}


Table A1 | Continued

Tissue AURATUS Best blast hit ID
DA depletion or receptor blockage

DA mimic

Accession

\section{MPTP + SCH $23390 \quad$ Sulpiride}

aMPT

\begin{tabular}{ll}
\hline Hyp & $07 m 24$ \\
Hyp & 22c24 \\
Hyp & $08 g 15$ \\
Hyp & $12 \mathrm{e} 04$ \\
Hyp & $24 k 14$ \\
Hyp & $22 \mathrm{~m} 10$ \\
Hyp & $09 b 02$ \\
Hyp & $03 j 12$
\end{tabular}

Hyp $03 f 23$

Hyp 23k24

Hyp 02i24

Hyp 03021

Hyp 24a12

Hyp $15 a 10$

Hyp 07b01

Hyp 20j14

Hyp $09 e 01$

Hyp 24j21

Hyp 03009

Hyp 10m11

Hyp 17n11

Hyp $02 g 12$

Hyp 03i20

Hyp 10d04

Hyp 23012

Hyp 08h01

Hyp 14b13

Hyp 19m14

Hyp $14 k 03$

Hyp $14 \mathrm{i04}$

Hyp 24012

Нyp $08 g 14$

Hyp 19d02

Hyp 03i10

Hyp 04j23

Hyp 13014

Hyp 22g07

Hyp 11p01

Hyp $19 f 13$

Hyp $14 \mathrm{m01}$

Hyp 12k14

Hyp 22011
Danio rerio non-metastatic cells 4 , protein expressed in (nme4), mRNA

Danio rerio SET translocation (myeloid

leukemia-associated) A (seta), mRNA

Danio rerio zgc:110605 (zgc:110605), mRNA

Danio rerio zgc:55886 (zgc:55886), mRNA

Danio rerio zgc:77060 (zgc:77060), mRNA

Danio rerio zgc:92169 (zgc:92169), mRNA

Danio rerio zgc:92371 (zgc:92371), mRNA

Danio rerio neuron-specific protein family

member 1 (brain neuron cytoplasmic protein 1)

mRNA

Deoxyribonuclease I-like 3

e3 Ubiquitin protein ligase

Ependymin

Ependymin

eph Receptor a7

Equilibrative nucleoside transporter 1

Eukaryotic translation elongation factor-1

gamma

Eukaryotic translation initiation factor 2, subunit

1 alpha

Fibronectin $1 b$

fk506-Binding protein $1 a$

Fructose-bisphosphate aldolase c

g Protein-coupled family group member c

Gamma-glutamyl cyclotransferase

Gasterosteus aculeatus clone cnb214-a06

mRNA sequence

Glutamine synthetase

Glutathione peroxidase 3

Glyceraldehyde 3-phosphate dehydrogenase

Glyceronephosphate-O-acyltransferase

Granulin 1

h2a Histone member y2

Heat shock protein 90 beta

HECT domain containing 1

Hexokinase I

High-density lipoprotein binding protein

Hydroxysteroid (17-beta) dehydrogenase 10

Immunoglobulin mu heavy chain

Jumonji domain containing 3

Latexin

Leucine-rich repeat (in flii) interacting protein 1

Leucine-rich repeat containing 58

loc548392 Protein

Malate dehydrogenase 1, NAD (soluble)

Male-specific protein

Map microtubule affinity-regulating kinase 4
1.4

1.3

$-1.3$

$-1.3$

$-1.4$

1.3

1.5

1.6

1.3

1.4

1.6

1.3

$-1.5$

$-1.3$

$-1.3$

13

1.4

1.3

1.3

1.3

1.2

1.4

2.0

$-1.6$

$-1.3$

$-1.4$

$-1.3$

1.6

$-1.4$

$-1.3$

1.5

1.3

1.2

$-1.3$

$-1.4$

$-1.3$

$-1.3$

1.5
SKF 38393 LY171555

$-1.7$

CA964093

$-1.6$

CA969283

$$
1.6
$$

CA970392

1.9

1.7

$-1.7$

$-1.6$

2.0

$-1.6$

1.3

CA966744

CA969922

CA969469

CA964765

FG392599

$-1.5$

DY231911

CA968074

DY231713

DY232010

CA969719

CA965545

CA966738

$-2.0$

2.3

CA966561

2.0

$-1.5$

$-1.6$

$-1.6$

$-1.7$

$-1.5$

$-1.5$

$-1.5$

$-2.1$

2.2

1.5

1.6

1.7

1.5

$-1.9$

1.6

2.2

$-1.5$

$-1.5$

1.6

$-1.7$

2.2

2.0

1.8

1.9

$-2.0$
CA964120

CA966789

FG392624

CA967701

CA965786

DY231579

DY231974

CA964192

CA968103

CA968696

CA964295

CA965061

CA964458

CA964417

CA969997

CA968690

1.3 CA965806

FG392590

FG392963

CF662717

CA969350

CF662658

CA969104

1.3 CA964750

CA970272

CA969512 
Table A1 | Continued

ID
Tissue AURATUS Best blast hit

DA depletion or receptor blockage

MPTP + SCH $23390 \quad$ Sulpiride

aMPT

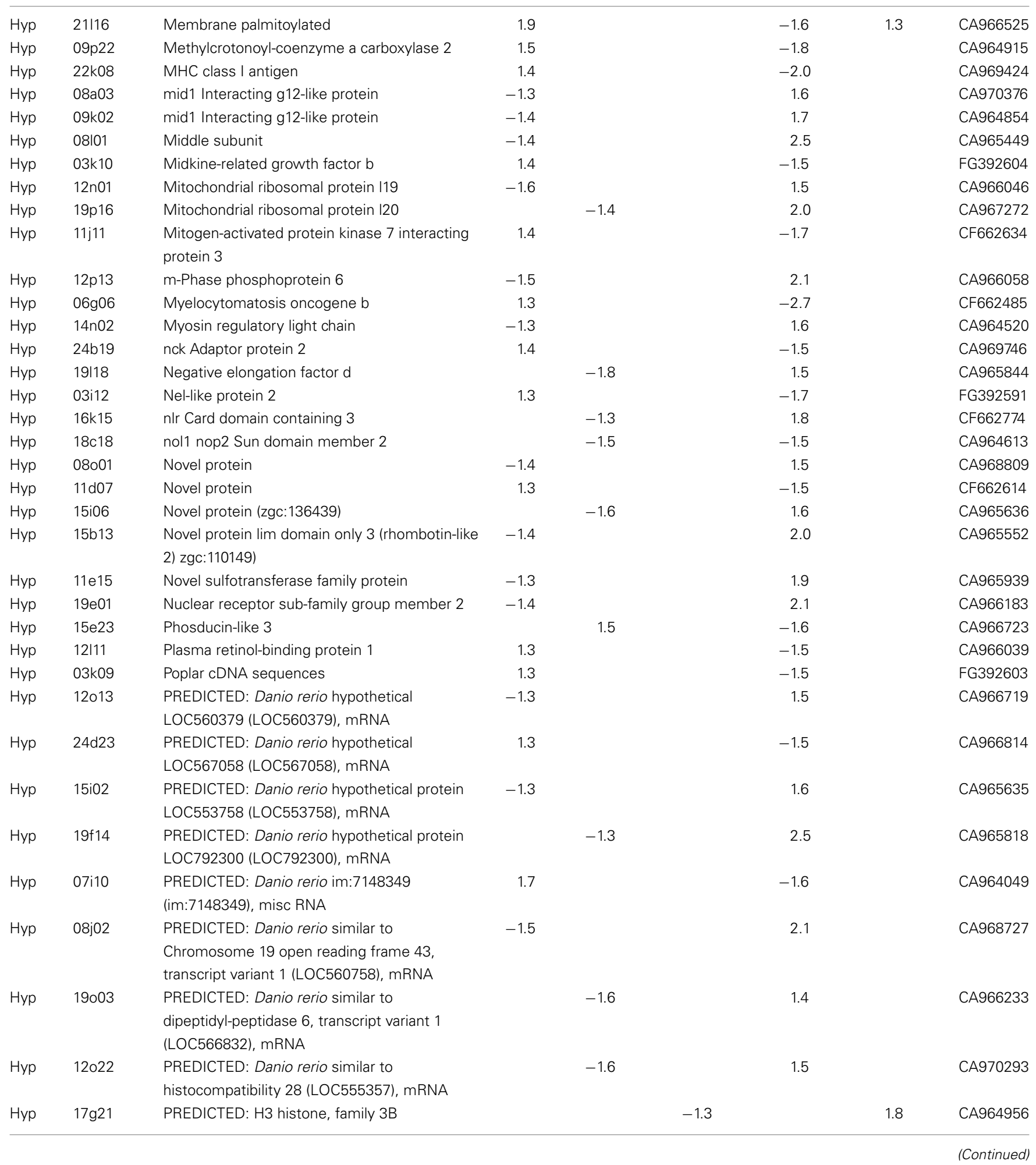

DA mimic Accession

\section{SKF $38393 \quad$ LY171555}


Table A1 | Continued

\begin{tabular}{|c|c|c|c|c|c|c|c|c|}
\hline \multirow[t]{2}{*}{ Tissue } & \multirow{2}{*}{$\begin{array}{l}\text { AURATUS } \\
\text { ID }\end{array}$} & \multirow[t]{2}{*}{ Best blast hit } & \multicolumn{3}{|c|}{ DA depletion or receptor blockage } & \multicolumn{2}{|c|}{ DA mimic } & \multirow[t]{2}{*}{ Accession } \\
\hline & & & $\begin{array}{l}\text { MPTP + } \\
\text { aMPT }\end{array}$ & SCH 23390 & Sulpiride & SKF 38393 & LY171555 & \\
\hline Hyp & 15014 & PREDICTED: hypothetical protein [Danio rerio] & -1.2 & & & 2.0 & & CA965715 \\
\hline Hyp & $22 \mathrm{~g} 11$ & $\begin{array}{l}\text { PREDICTED: hypothetical protein LOC337077, } \\
\text { partial [Danio rerio] }\end{array}$ & 1.3 & & & -2.0 & & CA969354 \\
\hline Hyp & 22p03 & Proteasome (macropain) 26s non- 4 & 1.4 & & & -1.6 & & CA969527 \\
\hline Hyp & 12b01 & Proteasome (macropain) alpha 5 & -1.5 & & & 2.0 & 1.3 & CA965983 \\
\hline Hyp & $12 \mathrm{i} 01$ & Purine nucleoside phosphorylase & -1.5 & & & 1.6 & & CA967769 \\
\hline Hyp & $22 \mathrm{~b} 23$ & Response gene to complement 32 & 1.3 & & & -2.0 & & CA969259 \\
\hline Hyp & $22 \mathrm{~g} 21$ & Ribosomal protein I13 & 1.5 & & & -1.7 & & CA969362 \\
\hline Hyp & $21 \mathrm{a} 01$ & sh3-Domain grb2-like 2 & -1.5 & & & 1.7 & 1.3 & CA967895 \\
\hline Hyp & 09g14 & si:ch211-Protein & -1.4 & & & 1.8 & & CA964823 \\
\hline Hyp & 11101 & $\begin{array}{l}\text { Siniperca chuatsi } 28 \mathrm{~S} \text { ribosomal RNA gene, } \\
\text { partial sequence }\end{array}$ & -1.5 & & & 1.8 & & CA966341 \\
\hline Hyp & $24 i 19$ & $\begin{array}{l}\text { StAR-related lipid transfer (START) domain } \\
\text { containing } 4\end{array}$ & 1.4 & & & -2.1 & 1.6 & CA969885 \\
\hline Hyp & 09n02 & $\begin{array}{l}\text { Sterol-c5-desaturase (fungal delta-5-desaturase) } \\
\text { homolog (cerevisiae) }\end{array}$ & -1.3 & & & 2.5 & & CA964885 \\
\hline Hyp & $12 \mathrm{p} 21$ & Surfeit 4 & & -1.5 & & 1.6 & & CA966062 \\
\hline Hyp & $21 g 17$ & Troponin c-type 2 & & -1.5 & & 1.6 & & CA967929 \\
\hline Hyp & $22 \mathrm{~g} 09$ & Tubulin alpha 8 like 4 & 1.3 & & & -1.8 & & CA969352 \\
\hline Hyp & 03023 & Tubulin beta-2c & 1.4 & & & -1.5 & & FG392672 \\
\hline Hyp & 17j23 & Tubulin beta-2c chain & 1.4 & & & -1.5 & & CA965774 \\
\hline Hyp & $14 \mathrm{f0} 2$ & u2 Small nuclear RNA auxiliary factor-1 & & -1.7 & & 2.4 & 1.3 & CA964363 \\
\hline Hyp & 22109 & Vacuolar protein sorting $13 \mathrm{c}$ & 1.3 & & & -1.5 & & CA969449 \\
\hline Hyp & $20 j 02$ & Vacuolar protein sorting $4 a$ & -1.5 & & & 1.7 & 1.6 & CA966560 \\
\hline Hyp & $14 j 12$ & Vimentin & 1.4 & & & -1.5 & & CA964445 \\
\hline Hyp & $24 \mathrm{i} 24$ & Vimentin & 1.4 & & & -1.7 & & CA969890 \\
\hline Hyp & $12 \mathrm{i} 13$ & Vitellogenin 2 & -1.3 & & & 1.4 & & CA967775 \\
\hline Hyp & $03 a 21$ & $\begin{array}{l}\text { Zebrafish DNA sequence from clone } \\
\text { ch1073-368i11 in linkage group complete } \\
\text { sequence }\end{array}$ & 1.4 & & & -2.0 & & DY231868 \\
\hline Hyp & $16 \mathrm{n} 18$ & $\begin{array}{l}\text { Zebrafish DNA sequence from clone } \mathrm{CH} 211- \\
11 \mathrm{~J} 2 \text { in linkage group } 7 \text {, complete sequence }\end{array}$ & & -1.3 & & 1.8 & & CA966457 \\
\hline Hyp & $19 \mathrm{e} 02$ & $\begin{array}{l}\text { Zebrafish DNA sequence from clone } \mathrm{CH} 211- \\
126 \mathrm{C} 2 \text { in linkage group } 14, \text { complete sequence }\end{array}$ & -1.4 & & & 2.0 & & CA965014 \\
\hline
\end{tabular}


Table A1 | Continued

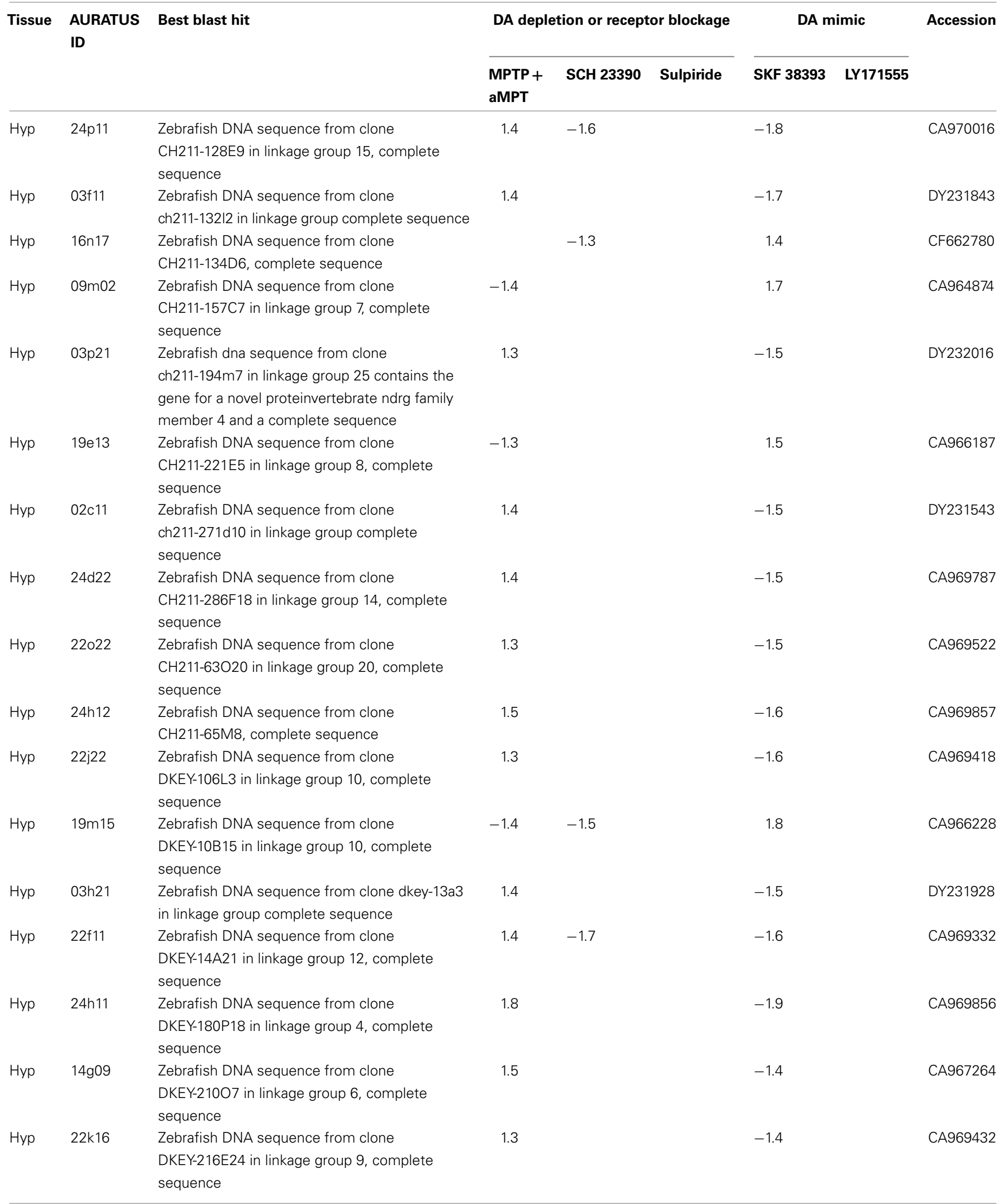


Table A1 | Continued

\begin{tabular}{|c|c|c|c|c|c|c|c|c|}
\hline \multirow[t]{2}{*}{ Tissue } & \multirow{2}{*}{$\begin{array}{l}\text { AURATUS } \\
\text { ID }\end{array}$} & \multirow[t]{2}{*}{ Best blast hit } & \multicolumn{3}{|c|}{ DA depletion or receptor blockage } & \multicolumn{2}{|c|}{ DA mimic } & \multirow[t]{2}{*}{ Accession } \\
\hline & & & $\begin{array}{l}\text { MPTP + } \\
\text { aMPT }\end{array}$ & SCH 23390 & Sulpiride & SKF 38393 & LY171555 & \\
\hline Hyp & $13 k 21$ & $\begin{array}{l}\text { Zebrafish DNA sequence from clone } \\
\text { DKEY-228N9 in linkage group 11, complete } \\
\text { sequence }\end{array}$ & 1.3 & & & -1.6 & & CA967861 \\
\hline Hyp & $15 f 02$ & $\begin{array}{l}\text { Zebrafish DNA sequence from clone } \\
\text { DKEY-242H9 in linkage group 18, complete } \\
\text { sequence }\end{array}$ & -1.4 & & & 1.6 & 1.3 & CA965596 \\
\hline Hyp & 18b02 & $\begin{array}{l}\text { Zebrafish DNA sequence from clone DKEY-3P10 } \\
\text { in linkage group } 23, \text { complete sequence }\end{array}$ & & -1.6 & & 1.6 & & CA968927 \\
\hline Hyp & $23 \mathrm{k} 09$ & $\begin{array}{l}\text { Zebrafish DNA sequence from clone } \\
\text { DKEY-40M6 in linkage group 16, complete } \\
\text { sequence }\end{array}$ & 1.3 & & & -1.5 & & CF662916 \\
\hline Hyp & 19008 & Zinc and double phd fingers family 2 & & -1.5 & & 1.5 & & CA965067 \\
\hline Hyp & $23 a 24$ & Zinc finger ccch-type containing $7 a$ & 2.0 & & & -2.3 & & CA967982 \\
\hline Hyp & $15 i 14$ & Zinc finger protein 782 & -1.3 & & & 2.0 & & CA965639 \\
\hline Hyp & $20 c 13$ & Zona pellucida glycoprotein & & -1.6 & & 1.7 & & CA966260 \\
\hline Tel & 12017 & ccaat Enhancer-binding protein beta & & & -1.6 & & 1.7 & CA967804 \\
\hline Tel & $12 \mathrm{e} 10$ & Leucine-rich ppr-motif containing & -1.8 & & & & 1.6 & CA970240 \\
\hline Tel & $14 \mathrm{f04}$ & $\begin{array}{l}\text { Solute carrier family } 2 \text { (facilitated glucose } \\
\text { fructose transporter) member } 5\end{array}$ & & & -1.3 & & 1.9 & CA964365 \\
\hline
\end{tabular}

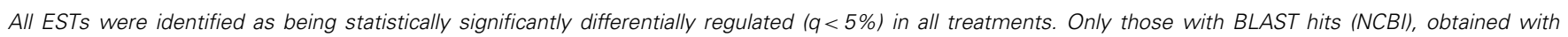

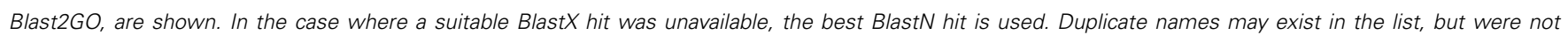

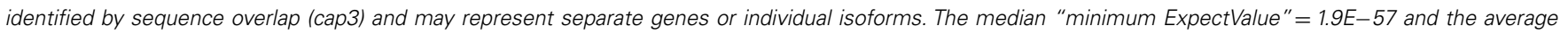
"mean similarity" $=84.8 \pm 1 \%$. 